\title{
Price and Service Competition between New and Remanufactured Products
}

\author{
Bin Wang ${ }^{1,2}$ and Jing Wang ${ }^{1}$ \\ ${ }^{1}$ School of Economics and Management, Beihang University, Beijing 100191, China \\ ${ }^{2}$ School of Economics and Management, Dezhou University, Shandong 253023, China \\ Correspondence should be addressed to Jing Wang; jim08@buaa.edu.cn
}

Received 30 December 2014; Revised 18 March 2015; Accepted 29 March 2015

Academic Editor: Qing (Cindy) Chang

Copyright (C) 2015 B. Wang and J. Wang. This is an open access article distributed under the Creative Commons Attribution License, which permits unrestricted use, distribution, and reproduction in any medium, provided the original work is properly cited.

\begin{abstract}
This paper sets two manufacturers on the market. One is traditional manufacturer, which produces new products, and the other remanufactures by recycling used products. Two manufacturers sell products to customers through one retailer and also provide product-related services. Three participators decide prices and service levels independently. We discuss the optimal decision of prices, service levels, demands, and profits in three scenarios: Manufacturers Stackelberg, Retailer Stackelberg, and Nash Equilibrium. We also study the influence of customer acceptance of remanufactured product $(\theta)$ on participators' decisions. With the increase of $\theta$, new product profit reduces; remanufactured product profit increases at the beginning and then decreases. Retailer profit grows steadily. In Manufacturers Stackelberg, new and remanufactured products can get the maximum profits, and retailer only has the minimum profit. In Retailer Stackelberg, retailer can get the maximum profit; new product only has the minimum profit and remanufactured product has the medium gain. In Nash Equilibrium, new product and retailer have the medium gains, and remanufactured product has the minimum profit.
\end{abstract}

\section{Introduction}

Generally, remanufacturing refers to recovering, decomposing, cleaning, and reproducing the used products and putting them into reuse. Some governments and environmental organizations encourage enterprises to engage in remanufacturing under the pressure of the environment and resource. Many companies have established recycling and remanufacturing logistics to collect used products. Remanufacturing not only reduces the burden on the environment, but also decreases the cost of production. According to Global Industry Analysts (2010), the global machinery industry remanufacturing output grows fast in recent years and it is expected it will reach $\$ 104.8$ billion in 2015. In USA, remanufacturing industry output value accounts for $0.4 \%$ of GDP. Other industries, such as printer cartridges, electrical equipment, electronic equipment, and furniture, also grow quickly in recent years (Hauser and Lund [1]).

So, with the rise of the remanufacturing industry, traditional companies must pay attention to the change. Their market strategies must be adjusted accordingly. For example,
HP has set up a department for recycling, remanufacturing, and selling. Its remanufactured products are almost comparable to new products on performance and prices are lower. It also provides warranty and related services on remanufactured products. Therefore, customers should choose between new and remanufactured products based on product information of prices and services.

In existing literatures, remanufactured product studies focus on recovery, price, cost, demand, and so on. There is little consideration of their direct competition with new product in the same market. In addition, the current studies concentrate on prices, but service, as a very important factor affecting customer demand, has attracted a lot of attention. In this paper, there are two manufacturers and one retailer on the same market. One manufacturer supplies new products and the other provides remanufactured products. Two companies sell products through one retailer and also provide product-related services to customers. We analyze their optimal decisions of prices, services, demands, and profits. We also discuss the impact of customer acceptance of remanufactured product on their decisions. 


\section{Literature Review}

Service as an important factor affecting demand has attracted more and more attention in theoretical and academic research. Iyer [2] examines how manufacturer coordinates channel distribution when two retailers compete with price and nonprice factors. It concludes that quantity discount is not enough to coordinate such a channel. Tsay and Agrawal [3] study a supply chain with two competing retailers and a common manufacturer in which both retailers provide products as well as service to customers. Thus, retailers sell the same products and compete with price and service. Raju and Zhang [4] show that a menu of two-part tariffs can coordinate a dominant retailer channel, but it is not always profit manufacturer. Only when retailer is sufficiently dominant, a menu of two-part tariffs can be a better choice than a quantity discount. Koulamas [5] studies that the manufacturers and retailers can use revenue-sharing policies to achieve channel coordination effectively. Many papers have also addressed service competition, such as $\mathrm{Ba}$ et al. [6], Bernstein and Federgruen [7], de Borger and van Dender [8], Darian et al. [9], Dan et al. [10], and Kurata and Nam [11].

Recently, studies have begun to pay attention to remanufacturing. They often analyzed the recycling effort or profitability with remanufacturing [12-22]. Savaskan et al. [20] study price decision and collection effort in a supply chain with three types of reverse channels for remanufacturing. The study examines the incentives provided to the customer in order to improve the collection of used items. Savaskan and van Wassenhove [21] consider a duopolistic competition with a retailer. It also discussed the interactions surrounding price decisions with respect to forward and reverse channels. Atasu et al. [12] examined remanufacturing as a marketing strategy. It considered several factors, such as cost savings, greenmarket segments, competition with new products, and product life cycle. The study found that a remanufactured product is more profitable under monopolistic competition. They also pointed out that smart price decision making is important as the manufacturer cannibalizes used products. Other recent studies include Debo et al. [13], Ferrer and Swaminathan [14], Majumder and Groenevelt [23], Mitra and Webster [17], and others, which have shed light on competition in closed-loop supply chains with remanufacturing. However, these studies only focus on price interaction but do not include service interaction.

\section{The Model}

3.1. Model Overview. This paper discusses a monopoly market where there are two manufacturers and one retailer. One manufacturer uses new raw materials to produce new products; the other collects used products and produces remanufactured products. Two manufacturers sell products at wholesale prices through the same retailer, and retailer sells two kinds of products to consumers at retail prices. Both products have the same functions $[20,21]$. Two manufacturers also provide product-related services to customers. Three participants decide prices and service levels independently. The model is shown in Figure 1.

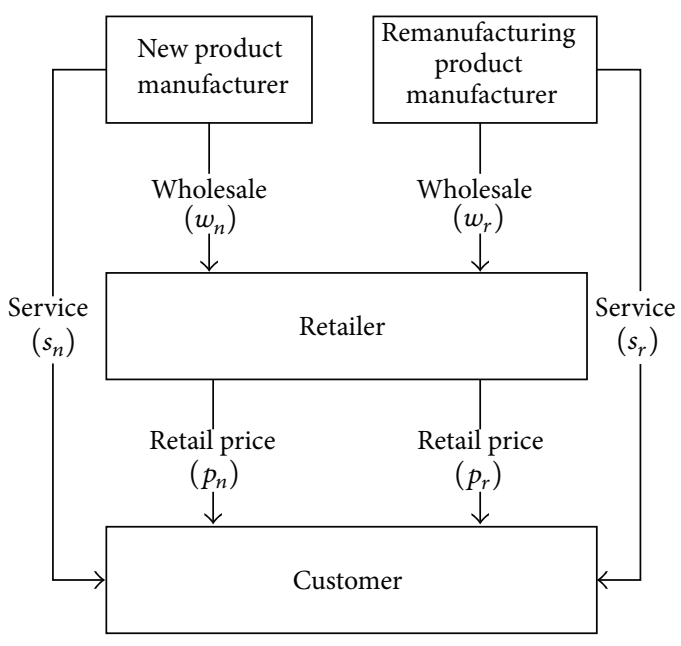

FIgURE 1: Description of the model.

Notations, variables, and parameters are defined as follows:

$\theta$ : consumer acceptance of remanufactured product $0<\theta<1$,

$c_{r}$ : unit production cost for remanufactured product,

$c_{n}$ : unit production cost for new product,

$q_{n}$ : demand of new product,

$q_{r}$ : demands of remanufactured product,

$a$ : potential market demand,

$s_{n}$ : service level of new product,

$s_{r}$ : service level of remanufactured product,

$p_{n}$ : retail price of new product,

$p_{r}$ : retail price of remanufactured product,

$w_{n}$ : wholesale price of new product,

$p_{r}$ : wholesale price of remanufactured product,

$\eta$ : service cost coefficient.

3.2. Assumptions. For simplifying the study, this paper presents the following basic assumptions.

Assumption 1 (the wish to purchase remanufactured product is less than buying new product for customer). Although new and remanufactured products are almost the same in the function, for ordinary consumer, there is also discrimination for remanufactured products $[12,14,23]$. Vast majority of consumers would like to choose new product rather than remanufactured product in the same prices and service levels. As described by Ferguson and Toktay [24], we define $\theta$ as the consumer acceptance of remanufactured product. $\theta=1$ indicates full acceptance of remanufactured products; $\theta=0$ means nonacceptance of remanufactured products completely; usually $0<\theta<1$. 
Assumption 2 (the unit production cost of remanufactured product is less than new product). $c_{r}$ means unit production cost for remanufactured product and $c_{n}$ means unit production cost for new product, where $c_{r}<c_{n}$. Such assumption is fit in actual situation. In fact, lower production cost is the main reason why many companies engaged in remanufacturing. Relative to the new product, it can save 30$70 \%$ of the cost of production (Gray and Charter [25]). Such assumption is also used in many literatures $[20,21,26]$.

Assumption 3 (companies have sufficient production capacity to meet market demand). This assumption means we do not consider the limit of production capacity. For new product manufacturer, there are unlimited raw materials in the market to purchase, so it has adequate production capacity to process. For remanufactured product manufacturer, the raw materials needed for its production have a variety of collecting channels, including new products sold on previous stage and similar waste products produced by other manufacturers. So, these collecting channels can meet the requirements of remanufacturing completely [20, 21, 27].

Assumption 4 (demand function). According to the economics theories and literatures $[3,24,28]$, when price reduces or service level improves, demand for product will increase; otherwise it will decrease. So, when there is only a single new product in market, the product demand function is

$$
q_{n}=a-p_{n}+s_{n}
$$

where $a$ represents the potential market demand. It is equal to the demand when price is zero, and no service is provided. We set $p_{n}$ as the price and $s_{n}$ as the service level of new product.

When remanufactured product appears on the market simultaneously, Ferguson and Toktay [24] give a price-based demand function:

$$
\begin{aligned}
& q_{n}=a-\frac{p_{n}-p_{r}}{1-\theta}, \\
& q_{r}=\frac{\theta p_{n}-p_{r}}{\theta(1-\theta)},
\end{aligned}
$$

where $p_{r}$ represents price of remanufactured product; $\theta$ means consumer acceptance of remanufactured product, and $0<\theta<1 ; q_{n}, q_{r}$ represent the demands of new and remanufactured product.

Combining formulas (1)-(2), we give the demand functions in this scenario:

$$
\begin{aligned}
& q_{n}=a-\frac{p_{n}-p_{r}-s_{n}+s_{r}}{1-\theta}, \\
& q_{r}=\frac{\theta p_{n}-p_{r}-\theta s_{n}+s_{r}}{\theta(1-\theta)},
\end{aligned}
$$

where $s_{n}, s_{r}$ represent service levels of new and remanufactured product.

Assumption 5 (cost and profit functions). Because $c_{n}$ means unit production cost of new product, total costs of production are $q_{n} c_{n}$. According to the literature, Tsay and Agrawal [3], total costs of services are proportional to their level square. So we set $\eta$ as service cost coefficient and $w_{n}$ as wholesale price; new product manufacturer profit function is

$$
\Pi_{n}\left(w_{n}, s_{n}\right)=\left(w_{n}-c_{n}\right) q_{n}-\frac{1}{2} \eta s_{n}^{2} .
$$

We set $c_{r}$ as remanufactured product unit production cost and $w_{r}$ as wholesale price. So profit of remanufactured product is

$$
\Pi_{r}\left(w_{r}, s_{r}\right)=\left(w_{r}-c_{r}\right) q_{r}-\frac{1}{2} \eta s_{r}^{2} .
$$

The retailer's profit is

$$
\Pi_{s}\left(p_{n}, p_{r}\right)=\left(p_{n}-w_{n}\right) q_{n}+\left(p_{r}-w_{r}\right) q_{r}
$$

Assumption 6. All the members have perfect information of the demands and the cost structures of each member. Based on this, they try to maximize their own profits.

3.3. Scenarios. We make the assumptions about strategic interactions, which can influence how the game is solved. In our research, three scenarios take place.

(1) Retailer Stackelberg. Retailer is dominant comparing to manufacturers and thus is the Stackelberg Leader.

(2) Manufacturers Stackelberg. Manufacturers are dominant comparing to retailer and thus are the Stackelberg Leaders.

(3) Nash Equilibrium. Three firms have equal bargaining powers and try to maximize their own profit.

\section{Retailer Stackelberg}

4.1. Decision Making Process and Result. In this scenario, retailer is the leader, and two manufacturers are in Nash Equilibrium. Retailer determines the optimal retail prices of new and remanufactured products firstly. Then, manufacturers, as the followers, according to retailer's decision, determine the optimal wholesale prices and service levels. The problemsolving process is as follows.

4.1.1. The Decision Making Process of New Product Manufacturer. $\Pi_{n}=\Pi_{n}\left(w_{n}, s_{n} \mid p_{n}, p_{r}\right)$ denotes the profit of new product manufacturer at this stage when it sets $w_{n}, s_{n}$, given earlier decisions by pricing $p_{n}, p_{r}$. According to (4), the first order conditions are shown as

$$
\begin{aligned}
& \frac{\partial \Pi_{n}}{\partial w_{n}}=a-\frac{p_{n}-p_{r}-s_{n}+s_{r}}{1-\theta}-\frac{w_{n}-c_{n}}{1-\theta}=0, \\
& \frac{\partial \Pi_{n}}{\partial s_{n}}=\frac{w_{n}-c_{n}}{1-\theta}-\eta s_{n}=0 .
\end{aligned}
$$


Then we check the Hessian for optimality:

$$
\begin{aligned}
& \frac{\partial^{2} \Pi_{n}}{\partial w_{n}^{2}}=-\frac{2}{(1-\theta)} ; \\
& \frac{\partial^{2} \Pi_{n}}{\partial s_{n}^{2}}=-\eta ; \\
& \frac{\partial^{2} \Pi_{n}}{\partial w_{n} \partial s_{n}}=\frac{1}{(1-\theta)}, \\
& \frac{2 \eta}{1-\theta}>\frac{1}{(1-\theta)^{2}} \Longleftrightarrow 2(1-\theta) \eta>1 .
\end{aligned}
$$

When $2(1-\theta) \eta>1$, the Hessian is a negative definite matrix and the second order condition is satisfied.

4.1.2. The Decision Making Process of Remanufactured Product Manufacturer. There, we can also get $\Pi_{r}=\Pi_{r}\left(w_{r}, s_{r} \mid p_{n}\right.$, $\left.p_{r}\right)$. According to (5), the first order conditions can be shown as

$$
\begin{aligned}
& \frac{\partial \Pi_{r}}{\partial w_{r}}=\frac{\theta p_{n}-p_{r}-\theta s_{n}+s_{r}}{\theta(1-\theta)}-\frac{w_{r}-c_{r}}{\theta(1-\theta)}=0, \\
& \frac{\partial \Pi_{r}}{\partial s_{r}}=\frac{w_{r}-c_{r}}{\theta(1-\theta)}-\eta s_{r}=0 .
\end{aligned}
$$

Then we check the Hessian for optimality:

$$
\begin{aligned}
& \frac{\partial^{2} \Pi_{r}}{\partial w_{r}^{2}}=-\frac{2}{\theta(1-\theta)} ; \\
& \frac{\partial^{2} \Pi_{r}}{\partial s_{r}^{2}}=-\eta ; \\
& \frac{\partial^{2} \Pi_{r}}{\partial w_{r} \partial s_{r}}=\frac{1}{\theta(1-\theta)}, \\
& \frac{2 \eta}{\theta(1-\theta)}>\frac{1}{\theta^{2}(1-\theta)^{2}} \Longleftrightarrow 2 \theta(1-\theta) \eta>1 .
\end{aligned}
$$

When $2 \theta(1-\theta) \eta>1$, the Hessian is a negative definite matrix and the second order condition is satisfied and (8) is also met.

According to (7) and (9), we can get

$$
\begin{aligned}
s_{n}= & \frac{[\theta(1-\theta) \eta-1] a-(\theta \eta-1) p_{n}+\theta \eta p_{r}}{\theta(1-\theta) \eta^{2}-(1+\theta) \eta+1}, \\
s_{r}= & \frac{\theta \eta p_{n}-(\eta-1) p_{r}-\theta a}{\theta(1-\theta) \eta^{2}-(1+\theta) \eta+1}, \\
w_{n}= & (1-\theta) \eta \frac{[\theta(1-\theta) \eta-1] a-(\theta \eta-1) p_{n}+\theta \eta p_{r}}{\theta(1-\theta) \eta^{2}-(1+\theta) \eta+1} \\
& +c_{n}, \\
w_{r}= & \theta(1-\theta) \eta \frac{\theta \eta p_{n}-(\eta-1) p_{r}-\theta a}{\theta(1-\theta) \eta^{2}-(1+\theta) \eta+1}+c_{r} .
\end{aligned}
$$

4.1.3. The Decision Making Process of Retailer. Having the information about the reaction functions of manufacturers, retailer would then use them to maximize its profit:

$$
\begin{aligned}
\Pi_{s}= & \Pi_{s}\left(p_{n}, p_{r} \mid w_{n}, w_{r}, s_{n}, s_{r}\right) \\
= & {\left[p_{n}-w_{n}\left(p_{n}, p_{r}\right)\right] q_{n}\left(p_{n}, p_{r}\right) } \\
& +\left[p_{r}-w_{r}\left(p_{n}, p_{r}\right)\right] q_{r}\left(p_{n}, p_{r}\right) .
\end{aligned}
$$

The first order conditions can be shown as

$$
\begin{aligned}
& \frac{\partial \Pi_{s}}{\partial p_{n}}=0 \\
& \frac{\partial \Pi_{s}}{\partial p_{r}}=0 .
\end{aligned}
$$
derived:

According to (13), the response prices for retailer can be

$$
\begin{aligned}
& p_{n}^{S^{*}}=\frac{A_{3} B_{2}-A_{2} B_{3}}{A_{2} B_{1}-A_{1} B_{2}}, \\
& p_{r}^{S^{*}}=\frac{A_{1} B_{3}-A_{3} B_{1}}{A_{2} B_{1}-A_{1} B_{2}},
\end{aligned}
$$

where

$$
\begin{aligned}
A_{1} & =-2 \eta\left[\theta^{2}\left(1-\theta^{2}\right) \eta^{2}-\theta(2-\theta) \eta+1\right] \\
A_{2} & =\theta \eta\left[5(1-\theta) \eta^{2}-\left(3+2 \theta-2 \theta^{2}\right) \eta+1\right] \\
A_{3} & =\eta\left[2 \theta^{2}\left(1-\theta^{2}\right) \eta^{2}-\theta(1-\theta)\left(2 \theta^{2}+\theta-4\right) \eta\right. \\
& +2-\theta] a+\left[\theta(1-\theta) \eta^{2}-(1+\theta) \eta+1\right](\theta \eta-1) \\
& \cdot c_{n}-\left[\theta(1-\theta) \eta^{2}-(1+\theta) \eta+1\right] \theta \eta c_{r}, \\
B_{1} & =5 \theta^{2}(1-\theta) \eta^{3}-\theta\left(3+\theta-2 \theta^{2}\right) \eta^{2}+\eta \\
B_{2} & =-2(2+\theta) \theta(1-\theta) \eta^{3}+2\left(1+3 \theta-2 \theta^{2}\right) \eta^{2} \\
& -\left(3+2 \theta-\theta^{2}\right) \eta+1, \\
B_{3} & =\left[-3 \theta^{2}(1-\theta) \eta^{2}+\theta\left(-3 \theta^{2}+3 \theta+1\right) \eta-\theta\right] a \\
& -\left[\theta(1-\theta) \eta^{2}-(1+\theta) \eta+1\right] \theta \eta c_{n}+\left[\theta(1-\theta) \eta^{2}\right. \\
& -(1+\theta) \eta+1](\eta-1) c_{r} .
\end{aligned}
$$

The letters marked with $*$ indicate the optimal solution.

According to these results and (11), we can obtain the response wholesale prices and service levels of manufacturers:

$$
\begin{aligned}
& s_{n}^{s^{*}}=\frac{[\theta(1-\theta) \eta-1] a-(\theta \eta-1) p_{n}^{S^{*}}+\theta \eta p_{r}^{s^{*}}}{\theta(1-\theta) \eta^{2}-(1+\theta) \eta+1}, \\
& s_{r}^{s^{*}}=\frac{\theta \eta p_{n}^{S^{*}}-(\eta-1) p_{r}^{s^{*}}-\theta a}{\theta(1-\theta) \eta^{2}-(1+\theta) \eta+1}
\end{aligned}
$$




$$
\begin{aligned}
& w_{n}^{S^{*}} \\
& =(1-\theta) \eta \frac{[\theta(1-\theta) \eta-1] a-(\theta \eta-1) p_{n}^{S^{*}}+\theta \eta p_{r}^{S^{*}}}{\theta(1-\theta) \eta^{2}-(1+\theta) \eta+1} \\
& +c_{n}, \\
& w_{r}^{S^{*}}=\theta(1-\theta) \eta \frac{\theta \eta p_{n}^{S^{*}}-(\eta-1) p_{r}^{S^{*}}-\theta a}{\theta(1-\theta) \eta^{2}-(1+\theta) \eta+1}+c_{r}, \\
& s_{n}^{S^{*}}=\frac{[\theta(1-\theta) \eta-1] a-(\theta \eta-1) p_{n}^{s^{*}}+\theta \eta p_{r}^{S^{*}}}{\theta(1-\theta) \eta^{2}-(1+\theta) \eta+1}, \\
& s_{r}^{s^{*}}=\frac{\theta \eta p_{n}^{S^{*}}-(\eta-1) p_{r}^{s^{*}}-\theta a}{\theta(1-\theta) \eta^{2}-(1+\theta) \eta+1}, \\
& w_{n}^{S^{*}} \\
& =(1-\theta) \eta \frac{[\theta(1-\theta) \eta-1] a-(\theta \eta-1) p_{n}^{S^{*}}+\theta \eta p_{r}^{S^{*}}}{\theta(1-\theta) \eta^{2}-(1+\theta) \eta+1} \\
& +c_{n} \\
& w_{r}^{S^{*}}=\theta(1-\theta) \eta \frac{\theta \eta p_{n}^{s^{*}}-(\eta-1) p_{r}^{S^{*}}-\theta a}{\theta(1-\theta) \eta^{2}-(1+\theta) \eta+1}+c_{r} . \\
& q_{n}^{S^{*}}=\eta \frac{[\theta(1-\theta) \eta-1] a-(\theta \eta-1) p_{n}^{S^{*}}+\theta \eta p_{r}^{S^{*}}}{\theta(1-\theta) \eta^{2}-(1+\theta) \eta+1}, \\
& q_{r}^{S^{*}}=\eta \frac{\theta \eta p_{n}^{S^{*}}-(\eta-1) p_{r}^{S^{*}}-\theta a}{\theta(1-\theta) \eta^{2}-(1+\theta) \eta+1} \\
& \Pi_{n}^{S^{*}}=\left[(1-\theta) \eta-\frac{1}{2}\right] \eta s_{n}^{N^{* 2}}, \\
& \Pi_{r}^{S^{*}}=\left[\theta(1-\theta) \eta-\frac{1}{2}\right] \eta s_{r}^{N^{* 2}}, \\
& \Pi_{s}^{S^{*}}=\left(p_{n}^{S^{*}}-w_{n}\right) q_{n}^{S^{*}}+\left(p_{r}^{S^{*}}-w_{r}^{S^{*}}\right) q_{r}^{S^{*}} .
\end{aligned}
$$

4.2. Effect of $\theta$ on Each Variable. According to (10) and ensuring $p>0, s>0$, we give two assumptions.

Assumption 7. $a$ is big enough compared to $\eta, c_{n}$, and $c_{r}$.

Assumption 8. $2 \eta \theta(1-\theta)$ is big enough compared to 1 .

These assumptions are applied to the entire following propositions. Proof of these propositions is in the Appendix.

Proposition $9\left(\partial s_{n}^{S^{*}} / \partial \theta>0, \partial s_{r}^{S^{*}} / \partial \theta>0\right)$. It means, with increase of the customer acceptance of remanufactured product, both new and remanufactured products will increase service levels.

Set $a=1000, \eta=20, c_{n}=100$, and $c_{r}=50 ; \theta$ increases from 0.4 to 0.8 . This group of dates learns from Ferrer and Swaminathan [14]. We use MATLAB to simulate
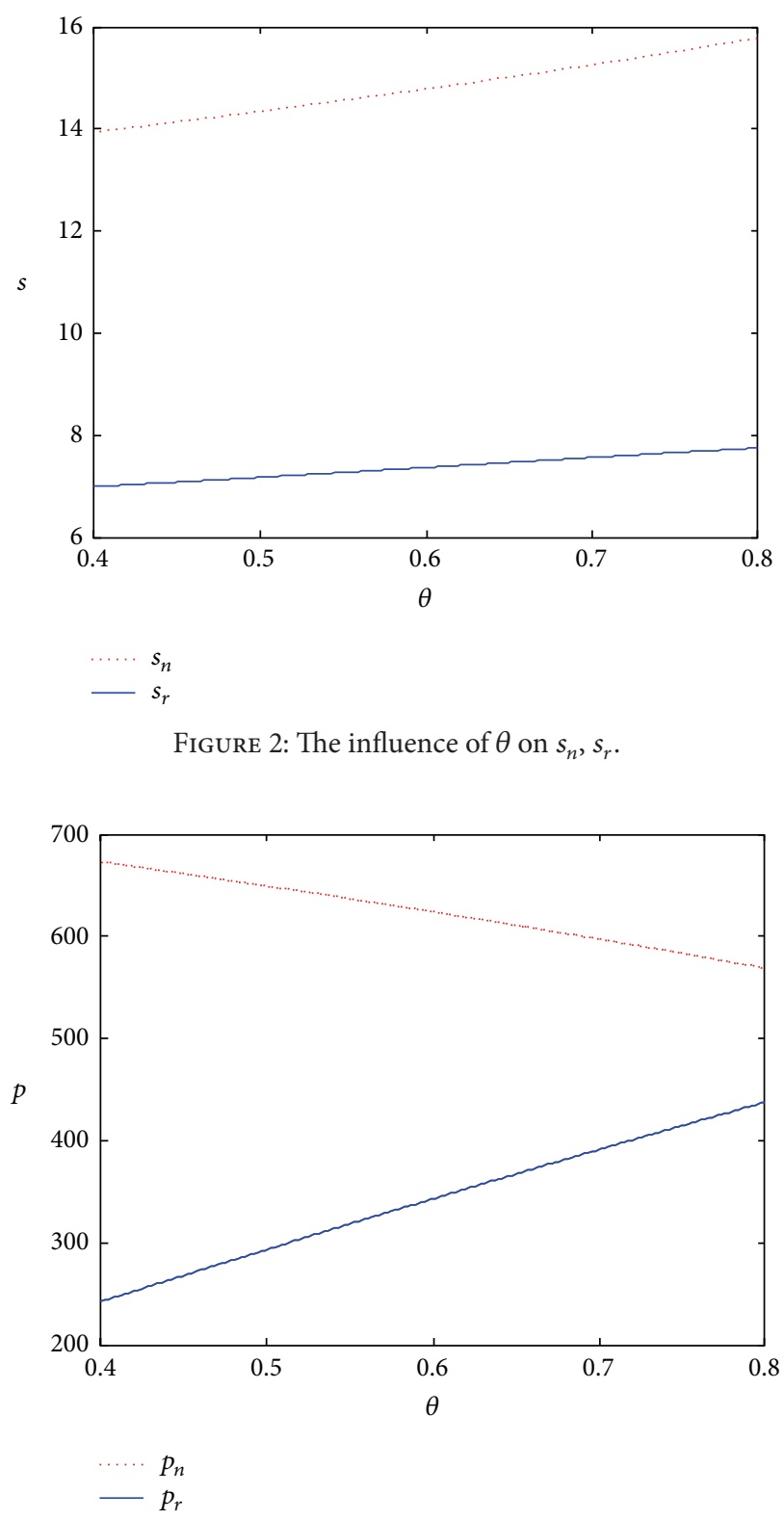

Figure 3: The influence of $\theta$ on $p_{n}, p_{r}$.

the change shown in Figure 2. For comparison, the following propositions all take this group of numerics to simulate.

With the rising of customer acceptance of remanufactured product, difference between new and remanufactured product becomes smaller. So there is little distinction between the two markets, and the competition becomes more intense. Both sides should have to improve service levels to stimulate requirements.

Proposition $10\left(\partial p_{n}^{S^{*}} / \partial \theta<0, \partial p_{r}^{S^{*}} / \partial \theta>0\right)$. It means, with the rise of $\theta$, new product price will reduce and remanufacturing product price increases. The simulation is shown in Figure 3.

For new product, with customer acceptance of remanufactured product rising, two kinds of products become more and more consistent. Retailer has to promote sales 


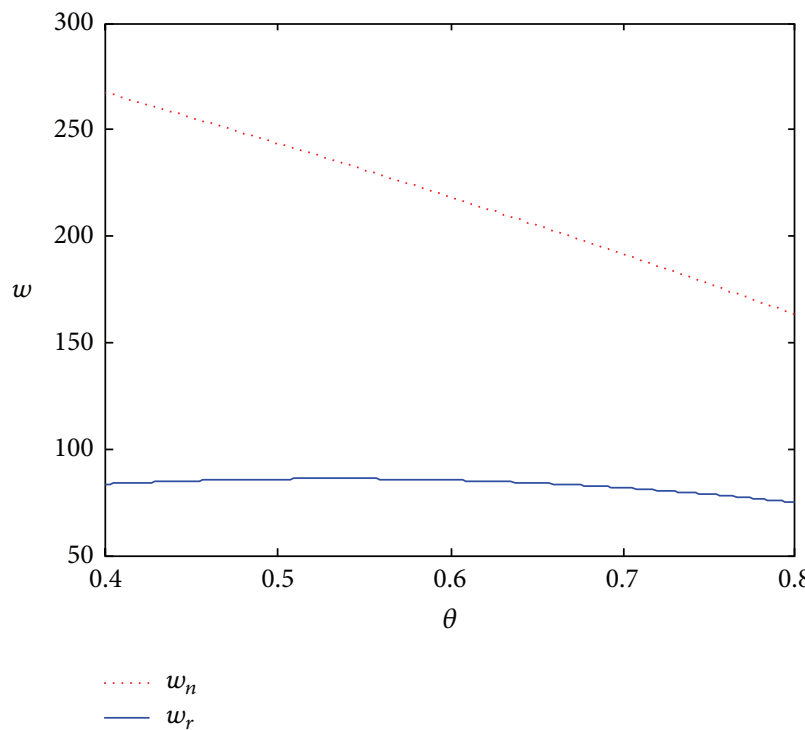

(a)

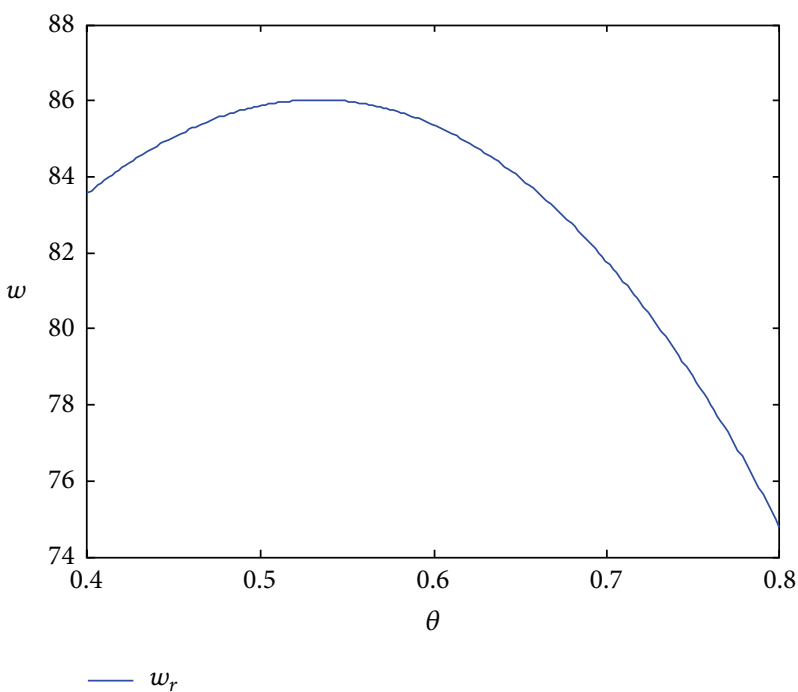

(b)

FIGURE 4: The influence of $\theta$ to $w_{n}, w_{r}$ (because change of $w_{r}$ is slight and cannot be shown clearly in one figure with $w_{n}$, the right figure only demonstrates the change of $w_{r}$. Some following figures also take this method).

by lowering price. For remanufactured product, rising of $\theta$ means more people accept it and potential demand increases. Retailer will raise the price and get more profit.

Proposition $11\left(\partial w_{n}^{S^{*}} / \partial \theta<0\right)$. It means, with the rise of $\theta$, wholesale price of new product will reduce, while the change of remanufactured product wholesale price has an inflection point $w_{r}^{N^{* *}}$. When $\theta \in\left(0, w_{r}^{S^{* *}}\right), \partial w_{r}^{S^{*}} / \partial \theta>0$; when $\theta \in\left(w_{r}^{S^{* *}}, 1\right)$, $\partial w_{r}^{S^{*}} / \partial \theta<0$, where $w_{r}^{S^{* *}} \approx 4-2 \sqrt{3}$. It means remanufactured product wholesale price increases at the beginning and then decreases. The simulation is shown in Figure 4.

For new product, with the rising of acceptance of remanufactured product, two products become more and more consistent, which leads to the decrease of the retail price.

For remanufactured product, as the customer acceptance of remanufactured product rises, there are two factors affecting product demand. Firstly, there is growing acceptance of remanufactured product, which means potential demand is increasing. Secondly, discrimination between remanufactured and new products becomes smaller. The two kinds of products competition are more intense, which leads to potential demand decrease. At the same time, increase of $\theta$ also means retailer's power is growing.

When $\theta$ is smaller $\left(\theta<w_{r}^{S^{* *}}\right)$, the first factor plays a leading role and retailer's power is smaller. So, with the potential growth of demand, remanufactured product can get more profit by raising wholesale prices. When $\theta$ is larger $(\theta>$ $\left.w_{r}^{S^{* *}}\right)$, the second factor plays a dominant role and retailer's power is greater. Although retail price increases, the retailer will still lower wholesale price to obtain more profit.

Proposition $12\left(\partial q_{n}^{S^{*}} / \partial \theta>0, \partial q_{r}^{S^{*}} / \partial \theta>0\right)$. It means, with the rise of $\theta$, new and remanufactured products sales both improve. The simulation is shown in Figure 5.

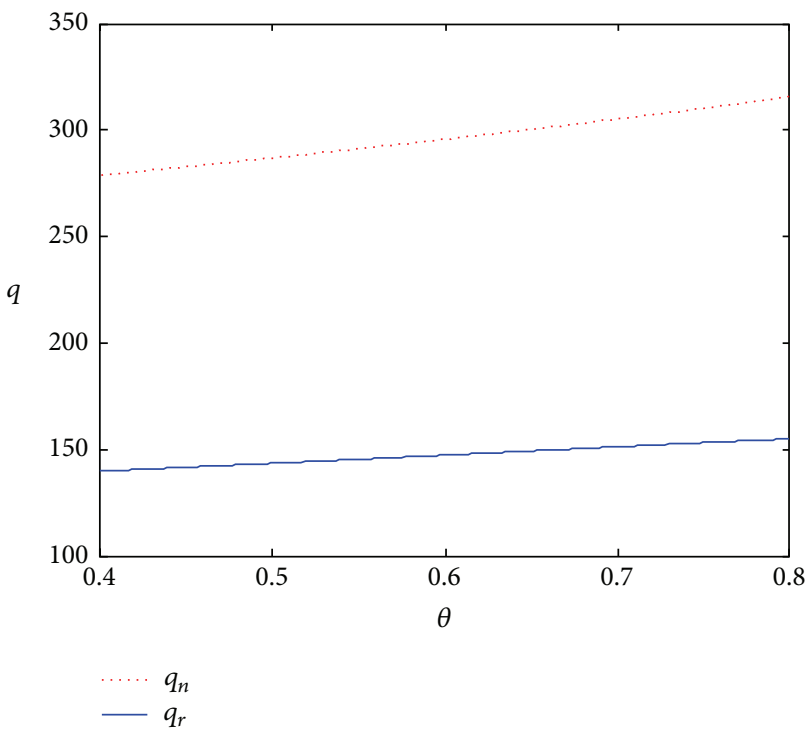

Figure 5: The influence of $\theta$ on $q_{n}, q_{r}$.

With the rising of $\theta$, new product lowers retail price and increases service level continuously, which makes demand increase.

Although remanufactured product raises the retail price, it also improves service level. The rising of $\theta$ means potential demand increases. So, there is also increase in demand.

Proposition $13\left(\partial \Pi_{n}^{S^{*}} / \partial \theta<0\right)$. It means, with the rise of $\theta$, the profit of new product will reduce, while the change of remanufactured product profit has an inflection point $\Pi_{r}^{S^{* *}}$. When $\theta \epsilon$ $\left(0, \Pi_{r}^{S^{* *}}\right), \partial \Pi_{r}^{S^{*}} / \partial \theta>0$; when $\theta \in\left(\Pi_{r}^{S^{* *}}, 1\right), \partial \Pi_{r}^{S^{*}} / \partial \theta<0$, where $\Pi_{r}^{S^{* *}} \approx 4 / 7$. It means remanufactured product profit increases at the beginning and then decreases. $\partial \Pi_{s}^{S^{*}} / \partial \theta>0$. It means 


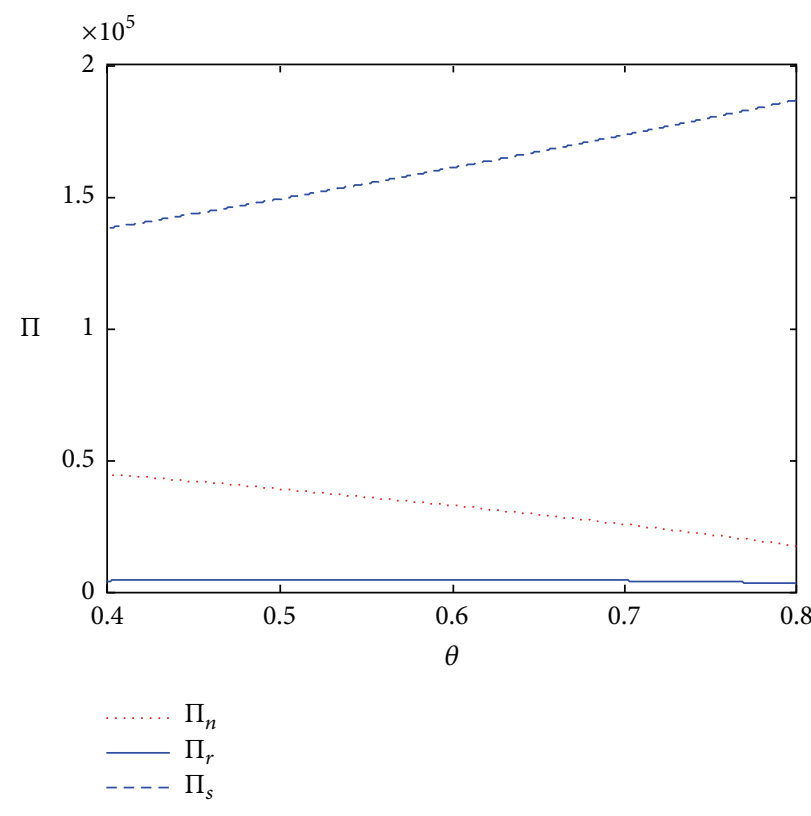

(a)

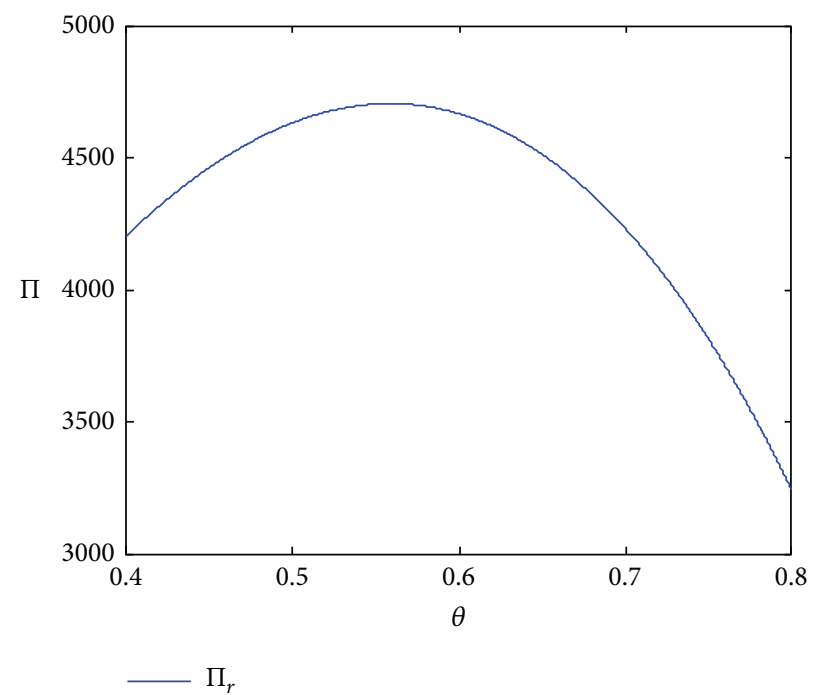

(b)

Figure 6: The influence of $\theta$ on $\Pi_{n}, \Pi_{r}$, and $\Pi_{s}$.

retailer profit increases continually. The simulation is shown in Figure 6.

For new product, with the rising of $\theta$, although sale increases, due to the decrease of wholesale price and increase of service level, the profit is decreasing.

For remanufactured products, at the beginning, due to the growth of wholesale price and sale, profit increases. But after reaching the inflection point, because wholesale price reduces and service cost increases gradually, little increase of sale is insufficient to cover the decline, so profit starts to decrease.

For retailer, profit of new product changes as follows. Although retail price decreases gradually, wholesale price also reduces, which means retailer transfers price loss to new product manufacturer. Because sale increases gradually, profit also increases. Remanufactured product profit changes as follows. At the beginning, although wholesale price rises, retail price will also increase, which means retailer transfers price loss to consumers. After reaching inflection point, retailer has more power. Despite retail price increases, retailer will still lower wholesale price. As sale is increasing, profit is also rising. In a word, retailer's total profit is increasing.

According to Proposition 13, we obtain the participators' expectations to $\theta$. New product manufacturer wants $\theta$ as low as possible. Smaller $\theta$ means little customer acceptance of remanufactured product; thus more customers chose new product. Smaller $\theta$ also signifies that two market segments are more clear and new product is a monopoly on the market. So, it can gain more profit.

However, remanufactured product manufacturer does not expect $\theta$ to go up even more. When $\theta$ is smaller, although its growth makes remanufactured product acceptance improve, thereby demand improves and profit increases.
However, when $\theta$ is larger, the growth also makes the distinction between remanufactured and new products smaller, so that they will come into one market and do direct competition, which leads to lower prices and higher service levels and reduces profit. So remanufactured product hopes $\theta$ remain in the inflection point $\left(\theta=\Pi_{r}^{S^{* *}}\right)$; then remanufactured product can earn maximum profit.

Retailer hopes $\theta$ become higher. The growth of $\theta$ means remanufactured and new products competition becomes more direct, and retailer acquires more power. So it can lower wholesale prices and gain more profit.

For the benefit of society, higher $q_{r}$ means more remanufactured products are sold, more waste materials are reused, and more social resources are saved. Because $\partial q_{r}^{S^{*}} / \partial \theta>$ $0, \theta$ should be as higher as possible, while remanufactured product manufacturer hopes it is equal to inflection point, which disaccords with the society. So how to balance the relationship between them deserves further research.

\section{Manufacturer Stackelberg}

5.1. Decision Making Process and Results. In this scenario, two manufacturers are leaders and have equal powers. Manufacturers determine the optimal wholesale prices and service levels of new and remanufactured products. Then retailer, as the follower, according to the manufacturers' decisions, determines the optimal retail prices. The problem-solving process is as follows.

5.1.1. The Decision Making Process of Retailer. $\Pi_{s}=$ $\Pi_{s}\left(p_{n}, p_{r} \mid w_{n}, w_{r}, s_{n}, s_{r}\right)$ denotes the profit of retailer at the stage when it sets $p_{n}$ and $p_{r}$, given earlier decisions of $w_{n}$, 
$w_{r}, s_{n}$, and $s_{r}$. According to (6), the first order conditions are shown as follows:

$$
\begin{aligned}
\frac{\partial \Pi_{s}}{\partial p_{n}} & =a-\frac{p_{n}-p_{r}-s_{n}+s_{r}}{1-\theta}-\frac{p_{n}-w_{n}}{1-\theta}+\frac{p_{r}-w_{r}}{1-\theta} \\
& =0, \\
\frac{\partial \Pi_{s}}{\partial p_{r}} & =\frac{\theta p_{n}-p_{r}-\theta s_{n}+s_{r}}{1-\theta}+\frac{p_{n}-w_{n}}{\theta(1-\theta)}-\frac{p_{r}-w_{r}}{\theta(1-\theta)} \\
& =0 .
\end{aligned}
$$

Then we check the Hessian for optimality. We have

$$
\begin{aligned}
\frac{\partial^{2} \Pi_{s}}{\partial p_{n}^{2}} & =\frac{-2}{1-\theta} ; \\
\frac{\partial^{2} \Pi_{s}}{\partial p_{r}^{2}} & =\frac{-2}{\theta(1-\theta)} ; \\
\frac{\partial^{2} \Pi_{s}}{\partial p_{n} \partial p_{r}} & =\frac{2}{1-\theta} .
\end{aligned}
$$

Because $4 / \theta(1-\theta)^{2}>4 /(1-\theta)^{2} \Leftrightarrow 0<\theta<1$, the Hessian is a negative definite matrix and the second order condition is satisfied.

According to (18), we can get

$$
\begin{aligned}
& p_{n}=\frac{a+s_{n}+w_{n}}{2}, \\
& p_{r}=\frac{\theta a+s_{r}+w_{r}}{2} .
\end{aligned}
$$

5.1.2. The Decision Making Process of Manufacturer. Having the information about the reaction function of retailer, manufacturers will use it to maximize their profits:

$$
\begin{aligned}
\Pi_{n} & =\Pi_{n}\left(w_{n}, s_{n} \mid p_{n}, p_{r}\right) \\
& =\left(w_{n}-c_{n}\right)\left(\frac{a}{2}+\frac{s_{n}-s_{r}-w_{n}+w_{r}}{2(1-\theta)}\right)-\frac{1}{2} \eta s_{n}^{2} \\
\Pi_{r} & =\Pi_{r}\left(w_{r}, s_{r} \mid p_{n}, p_{r}\right) \\
& =\left(w_{r}-c_{r}\right)\left(\frac{-\theta s_{n}+s_{r}+\theta w_{n}-w_{r}}{2 \theta(1-\theta)}\right)-\frac{1}{2} \eta s_{r}^{2} .
\end{aligned}
$$

For new product manufacturer, the first order conditions are shown as

$$
\begin{aligned}
& \frac{\partial \Pi_{n}}{\partial w_{n}}=\frac{a}{2}+\frac{s_{n}-s_{r}-w_{n}+w_{r}}{2(1-\theta)}-\frac{w_{n}-c_{n}}{2(1-\theta)}=0, \\
& \frac{\partial \Pi_{n}}{\partial s_{n}}=\frac{w_{n}-c_{n}}{2(1-\theta)}-\eta s_{n}=0 .
\end{aligned}
$$

For remanufactured product manufacturer

$$
\begin{aligned}
& \frac{\partial \Pi_{n}}{\partial s_{n}}=\frac{w_{n}-c_{n}}{2(1-\theta)}-\eta s_{n}=0, \\
& \frac{\partial \Pi_{n}}{\partial s_{n}}=\frac{w_{n}-c_{n}}{2(1-\theta)}-\eta s_{n}=0 .
\end{aligned}
$$

Then we check the Hessian for optimality. We have

$$
\begin{aligned}
\frac{\partial^{2} \Pi_{n}}{\partial w_{n}^{2}} & =\frac{-1}{1-\theta}, \\
\frac{\partial^{2} \Pi_{n}}{\partial s_{n}^{2}} & =-\eta, \\
\frac{\partial^{2} \Pi_{n}}{\partial w_{n} \partial s_{n}} & =\frac{1}{2(1-\theta)}, \\
\frac{\partial^{2} \Pi_{r}}{\partial w_{r}^{2}} & =-\frac{1}{\theta(1-\theta)}, \\
\frac{\partial^{2} \Pi_{r}}{\partial s_{r}^{2}} & =-\eta, \\
\frac{\partial^{2} \Pi_{r}}{\partial w_{r} \partial s_{r}} & =\frac{1}{2 \theta(1-\theta)}, \\
\frac{\eta}{1-\theta} & >\frac{1}{4(1-\theta)^{2}} \Longleftrightarrow 4(1-\theta) \eta>1, \\
\frac{\eta}{\theta(1-\theta)} & >\frac{1}{4 \theta^{2}(1-\theta)^{2}} \Longleftrightarrow 4 \theta(1-\theta) \eta>1 .
\end{aligned}
$$

So when $4 \theta(1-\theta) \eta>1$ the Hessian is a negative definite matrix and the second order condition is satisfied.

According to (22)-(23), the responses for manufacturers are derived:

$$
\begin{aligned}
& s_{n}^{M^{*}} \\
& =\frac{[4 \theta(1-\theta) \eta-1] a+2 \theta \eta c_{r}-[2 \theta(2-\theta) \eta-1] c_{n}}{4 \theta(1-\theta)(4-\theta) \eta^{2}-2\left(2+\theta-\theta^{2}\right) \eta+1}, \\
& s_{r}^{M^{*}} \\
& =\frac{\theta[2(1-\theta) \eta-1] a+2 \theta \eta c_{n}-[2(2-\theta) \eta-1] c_{r}}{4 \theta(1-\theta)(4-\theta) \eta^{2}-2\left(2+\theta-\theta^{2}\right) \eta+1}, \\
& w_{n}^{M^{*}} \\
& =2(1-\theta) \eta \\
& \quad \cdot \frac{[4 \theta(1-\theta) \eta-1] a+2 \theta \eta c_{r}-[2 \theta(2-\theta) \eta-1] c_{n}}{4 \theta(1-\theta)(4-\theta) \eta^{2}-2\left(2+\theta-\theta^{2}\right) \eta+1} \\
& \quad+c_{n}, \\
& w_{r}^{M^{*}} \\
& =2 \theta(1-\theta) \eta \\
& \quad+\frac{\theta[2(1-\theta) \eta-1] a+2 \theta \eta c_{n}-[2(2-\theta) \eta-1] c_{r}}{4 \theta(1-\theta)(4-\theta) \eta^{2}-2\left(2+\theta-\theta^{2}\right) \eta+1} \\
& +c_{r} .
\end{aligned}
$$


Using the results and (20), we can obtain the responses of retailer:

$$
\begin{aligned}
& p_{n}^{M^{*}}=\frac{a+[2(1-\theta) \eta+1] s_{n}^{M^{*}}+c_{n}}{2}, \\
& p_{r}^{M^{*}}=\frac{\theta a+[2 \theta(1-\theta) \eta+1] s_{r}^{M^{*}}+c_{r}}{2} .
\end{aligned}
$$

Then, we can get

$$
\begin{aligned}
& q_{n}^{M^{*}} \\
& =\eta \frac{[4 \theta(1-\theta) \eta-1] a+2 \theta \eta c_{r}-[2 \theta(2-\theta) \eta-1] c_{n}}{4 \theta(1-\theta)(4-\theta) \eta^{2}-2\left(2+\theta-\theta^{2}\right) \eta+1}, \\
& q_{r}^{M^{*}} \\
& =\eta \frac{\theta[2(1-\theta) \eta-1] a+2 \theta \eta c_{n}-[2(2-\theta) \eta-1] c_{r}}{4 \theta(1-\theta)(4-\theta) \eta^{2}-2\left(2+\theta-\theta^{2}\right) \eta+1}, \\
& \Pi_{n}^{M^{*}}=\left[2(1-\theta) \eta-\frac{1}{2}\right] \eta s_{n}^{M^{* 2}}, \\
& \Pi_{r}^{M^{*}}=\left[2 \theta(1-\theta) \eta-\frac{1}{2}\right] \eta s_{r}^{M^{* 2}}, \\
& \Pi_{s}^{M^{*}} \\
& =\frac{\eta}{2}\left\{a-[2(1-\theta) \eta-1] s_{n}^{M^{*}}\right\} s_{n}^{M^{*}} \\
& \quad+\frac{\eta}{2}\left\{\theta a-[2 \theta(1-\theta) \eta-1] s_{r}^{M^{*}}\right\} s_{r}^{M^{*}} .
\end{aligned}
$$

\subsection{Effect of $\theta$ on Each Variable}

Proposition $14\left(\partial s_{n}^{M^{*}} / \partial \theta>0, \partial s_{r}^{M^{*}} / \partial \theta>0\right)$. It means, with increase of the customer acceptance of remanufactured product, both new and remanufactured products will increase service levels. The simulation is shown in Figure 7.

This proposition is similar to Proposition 9. Because the increase of $\theta$ makes difference of them smaller and competition intense, both new and remanufactured products should have to improve service levels.

Proposition $15\left(\partial p_{n}^{M^{*}} / \partial \theta<0, \partial p_{r}^{M^{*}} / \partial \theta>0\right)$. It means, with the rise of $\theta$, retail price of new product will reduce, and remanufactured product price increases. The simulation is shown in Figure 8.

This proposition is similar to Proposition 10. For new product, retailer lowers price to promote demand. For remanufactured product, because of the increase of acceptance, retailer will raise price to get more profit.

Proposition $16\left(\partial w_{n}^{M^{*}} / \partial \theta<0\right)$. It means, with the rise of $\theta$, wholesale price of new product will reduce, while the change of remanufactured product wholesale price has an inflection point $w_{r}^{M^{* *}}$. When $\theta \in\left(0, w_{r}^{M^{* *}}\right), \partial w_{r}^{M^{*}} / \partial \theta>0$, and when $\theta \in\left(w_{r}^{M^{* *}}, 1\right), \partial w_{r}^{M^{*}} / \partial \theta<0$, where $w_{r}^{M^{* *}} \approx 4-2 \sqrt{3}$.

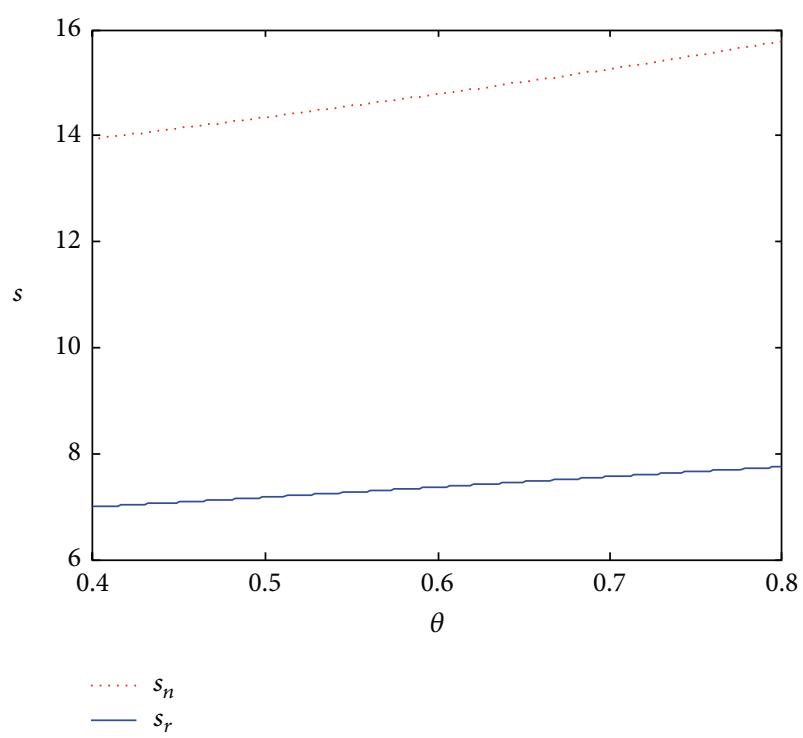

FIGURE 7: The influence of $\theta$ on $s_{n}, s_{r}$.

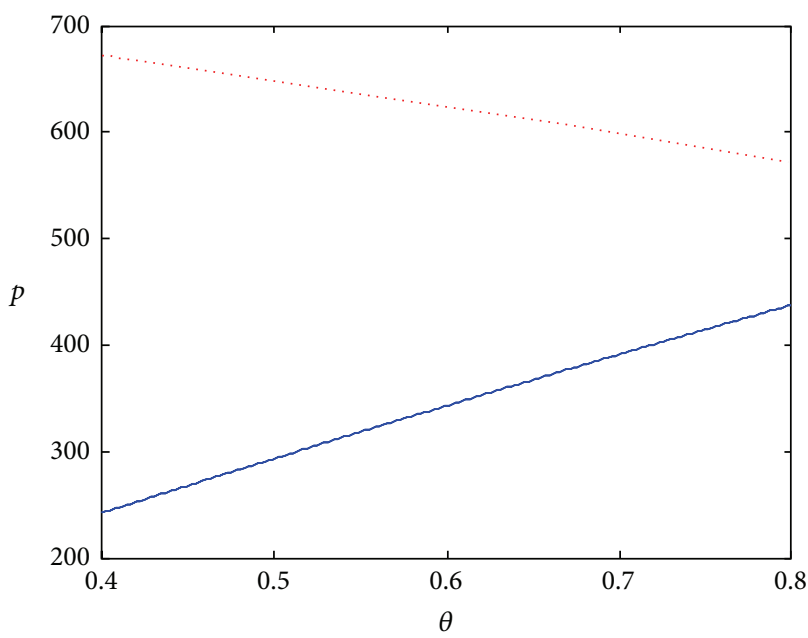

$p_{n}$
$-p_{r}$

FIGURE 8: The influence of $\theta$ on $p_{n}, p_{r}$.

It means remanufactured product wholesale price increases at the beginning and then decreases. The simulation is shown in Figure 9.

This proposition is similar to Proposition 11. When $\theta$ is small, the potential demand growth of remanufactured product plays a leading role, so remanufactured product can get more profit by increasing wholesale price. When $\theta$ is larger, retailer has more power. Remanufactured product has to lower wholesale price.

Proposition $17\left(\partial q_{n}^{M^{*}} / \partial \theta>0, \partial q_{r}^{M^{*}} / \partial \theta>0\right)$. It means, with the rise of $\theta$, new and remanufactured products' sales both improve. The simulation is shown in Figure 10. 


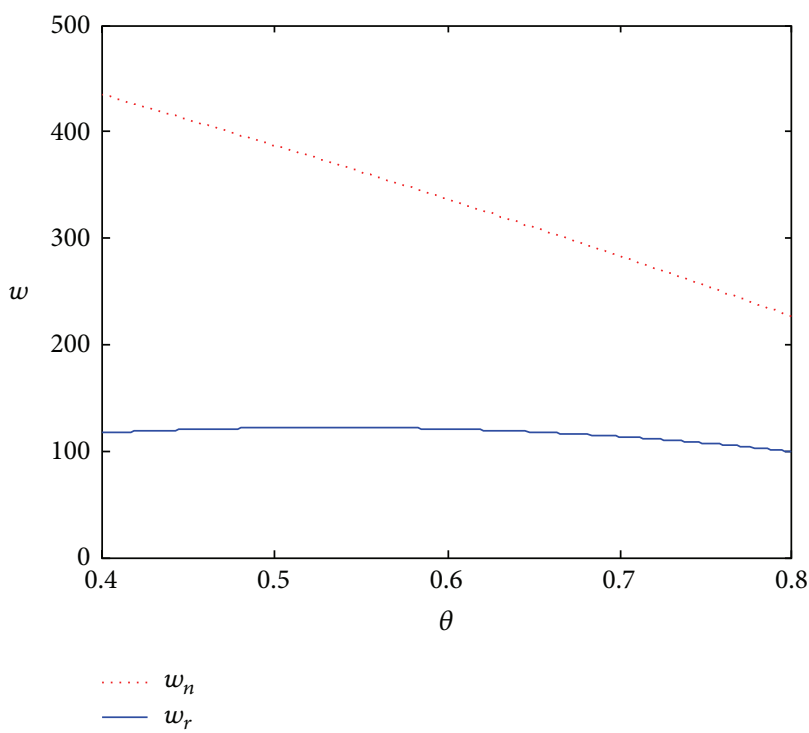

(a)

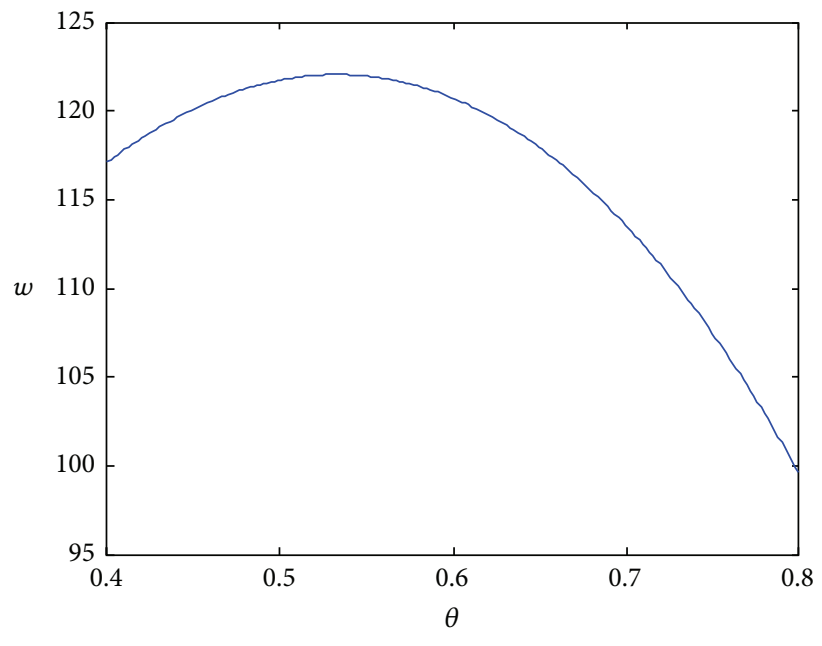

$-w_{r}$

(b)

FIGURE 9: The influence of $\theta$ on $w_{n}, w_{r}$.

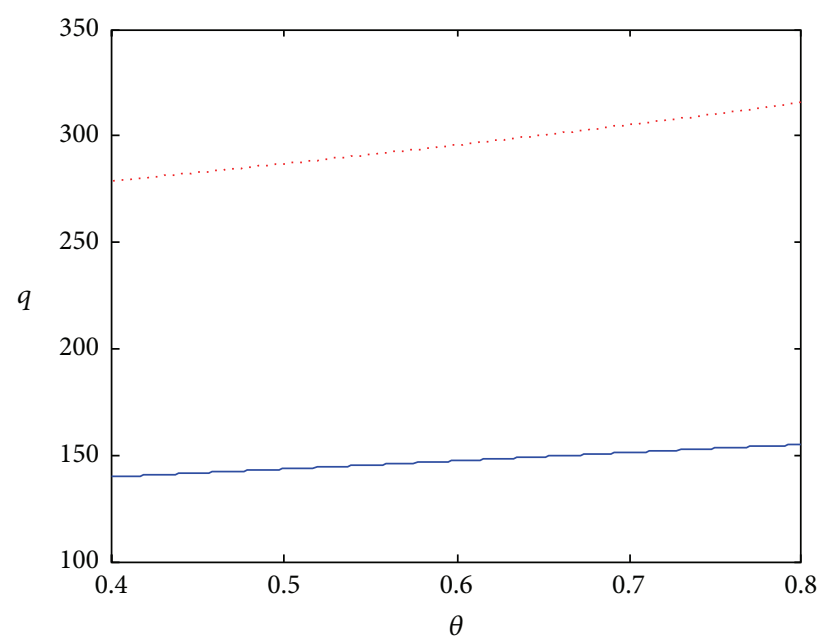

$q_{n}$

FIgURE 10: The influence of $\theta$ on $q_{n}, q_{r}$.

This proposition is similar to Proposition 12. With the increase of $\theta$, new product increases sales by improving service level and lowering retail price; remanufactured product increases acceptance and raises service level to stimulate demand.

Proposition $18\left(\partial \Pi_{n}^{M^{*}} / \partial \theta<0\right)$. It means, with the rise of $\theta$, the profit of new product will reduce. The change of remanufactured product profit has an inflection point $\Pi_{r}^{M^{* *}}$. When $\theta \in$ $\left(0, \Pi_{r}^{M^{* *}}\right), \partial \Pi_{r}^{M^{*}} / \partial \theta>0$; when $\theta \in\left(\Pi_{r}^{M^{* *}}, 1\right), \partial \Pi_{r}^{M^{*}} / \partial \theta<0$, where $\Pi_{r}^{M^{* *}} \approx 4 / 7$. It means remanufactured product profit increases at the beginning and then decreases. $\partial \Pi_{s}^{M^{*}} / \partial \theta>0$.
It means, with the rise of $\theta$, retailer profit increases. The simulation is shown in Figure 11.

This proposition is similar to Proposition 13. The reasons and consequences do not repeat.

\section{Nash Equilibrium}

6.1. Decision Making Process and Results. In Nash Equilibrium, no one occupies leading power. All the participators have equal power and make decisions simultaneously. The decision variables are $w_{n}, s_{n}, w_{r}, s_{r}$, and $p_{n}, p_{r}$. The calculations are as follows:

$$
\begin{aligned}
& \frac{\partial \Pi_{n}}{\partial w_{n}}=q_{n}-\frac{w_{n}-c_{n}}{1-\theta}=0, \\
& \frac{\partial \Pi_{n}}{\partial s_{n}}=\frac{w_{n}-c_{n}}{1-\theta}-\eta s_{n}=0, \\
& \frac{\partial \Pi_{r}}{\partial w_{r}}=q_{r}-\frac{w_{r}-c_{r}}{\theta(1-\theta)}=0, \\
& \frac{\partial \Pi_{r}}{\partial s_{r}}=\frac{w_{r}-c_{r}}{\theta(1-\theta)}-\eta s_{r}=0, \\
& \frac{\partial \Pi_{s}}{\partial p_{n}}=q_{n}-\frac{p_{n}-w_{n}}{1-\theta}+\frac{p_{r}-w_{r}}{1-\theta}=0, \\
& \frac{\partial \Pi_{s}}{\partial p_{r}}=\frac{p_{n}-w_{n}}{1-\theta}+q_{r}-\frac{p_{r}-w_{r}}{\theta(1-\theta)}=0 .
\end{aligned}
$$

Then we check the Hessian for optimality:

$$
\begin{aligned}
& \frac{\partial^{2} \Pi_{n}}{\partial w_{n}^{2}}=-\frac{2}{1-\theta}, \\
& \frac{\partial^{2} \Pi_{n}}{\partial s_{n}^{2}}=-\eta,
\end{aligned}
$$




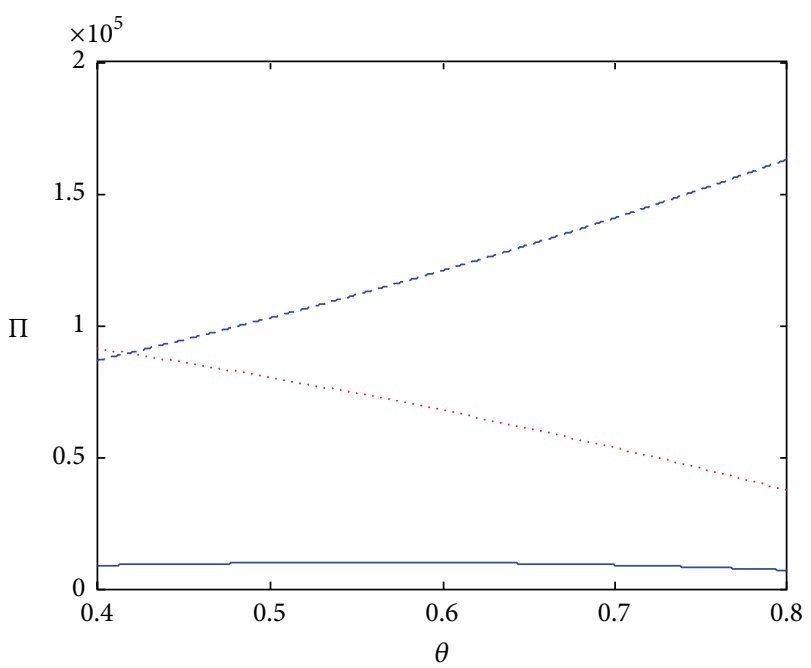

$\Pi_{n}$

$-\Pi_{r}$

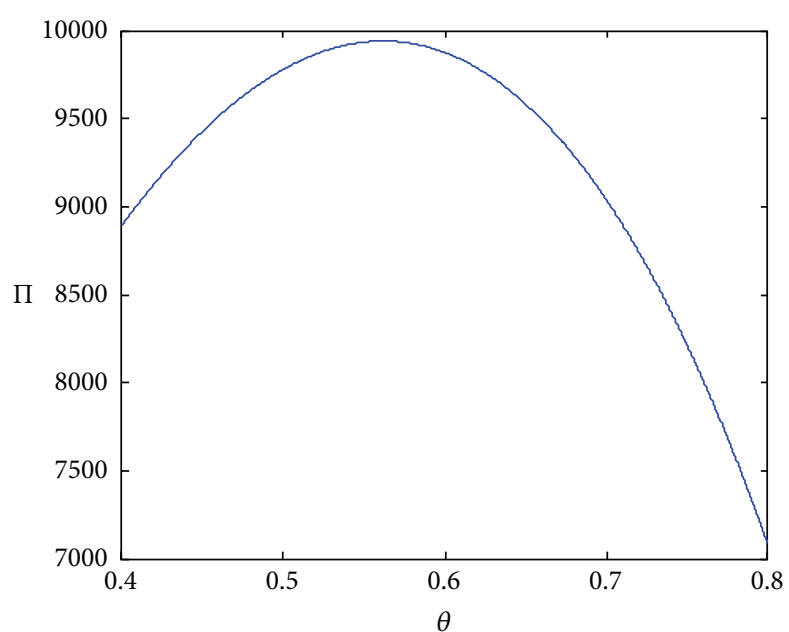

$\Pi_{r}$

(a)

(b)

Figure 11: The influence of $\theta$ on $\Pi_{n}, \Pi_{r}$, and $\Pi_{s}$.

$$
\begin{aligned}
& \frac{\partial^{2} \Pi_{n}}{\partial w_{n} \partial s_{n}}=\frac{1}{1-\theta} ; \\
& \frac{\partial^{2} \Pi_{r}}{\partial w_{r}^{2}}=-\frac{2}{\theta(1-\theta)}, \\
& \frac{\partial^{2} \Pi_{r}}{\partial s_{r}^{2}}=-\eta, \\
& \frac{\partial^{2} \Pi_{r}}{\partial w_{r} \partial s_{r}}=\frac{1}{\theta(1-\theta)} ; \\
& \frac{\partial^{2} \Pi_{s}}{\partial p_{n}^{2}}=-\frac{2}{1-\theta}, \\
& \frac{\partial^{2} \Pi_{s}}{\partial p_{r}^{2}}=-\frac{2}{\theta(1-\theta)}, \\
& \frac{\partial^{2} \Pi_{s}}{\partial p_{n} \partial p_{r}}=\frac{2}{1-\theta}, \\
& \frac{2 \eta}{1-\theta}-\frac{1}{(1-\theta)^{2}}>0 \Longleftrightarrow 2 \eta(1-\theta)>1, \\
& \frac{2 \eta}{\theta(1-\theta)}-\frac{1}{\theta^{2}(1-\theta)^{2}}>0 \Longleftrightarrow 2 \eta \theta(1-\theta)>1,
\end{aligned}
$$

When $2 \eta \theta(1-\theta)>1$ the Hessians are negative definite matrixes and second order conditions are satisfied.
According to (28), we can calculate the optimal decisions and results in this scenario:

$$
\begin{aligned}
& s_{n}^{N^{*}}=\frac{3 \theta(1-\theta)^{2} \eta a}{\theta(1-\theta) \eta[(9-\theta)(1-\theta) \eta-2]} \\
& +\frac{-\theta[(3-\theta)(1-\theta) \eta+1] c_{n}+[2 \theta(1-\theta) \eta+1] c_{r}}{\theta(1-\theta) \eta[(9-\theta)(1-\theta) \eta-2]} \\
& s_{r}^{N^{*}}=\frac{\theta(1-\theta)^{2} \eta a}{\theta(1-\theta) \eta[(9-\theta)(1-\theta) \eta-2]} \\
& +\frac{\theta[4(1-\theta) \eta-1] c_{n}-[(3+\theta)(1-\theta) \eta-1] c_{r}}{\theta(1-\theta) \eta[(9-\theta)(1-\theta) \eta-2]} \\
& w_{n}^{N^{*}}=\frac{3 \theta(1-\theta)^{2} \eta a}{\theta[(9-\theta)(1-\theta) \eta-2]} \\
& +\frac{-\theta[(3-\theta)(1-\theta) \eta+1] c_{n}+[2 \theta(1-\theta) \eta+1] c_{r}}{\theta[(9-\theta)(1-\theta) \eta-2]} \\
& +c_{n} \\
& w_{r}^{N^{*}}=\frac{\theta(1-\theta)^{2} \eta a}{(9-\theta)(1-\theta) \eta-2} \\
& +\frac{\theta[4(1-\theta) \eta-1] c_{n}-[(3+\theta)(1-\theta) \eta-1] c_{r}}{(9-\theta)(1-\theta) \eta-2} \\
& +c_{r} \\
& p_{n}^{N^{*}}=\eta\left[(2-\theta) s_{n}^{N^{*}}+\theta s_{r}^{N^{*}}\right]+c_{n}, \\
& p_{r}^{N^{*}}=\eta\left[\theta s_{n}^{N^{*}}+\theta(2-\theta) s_{r}^{N^{*}}\right]+c_{r},
\end{aligned}
$$




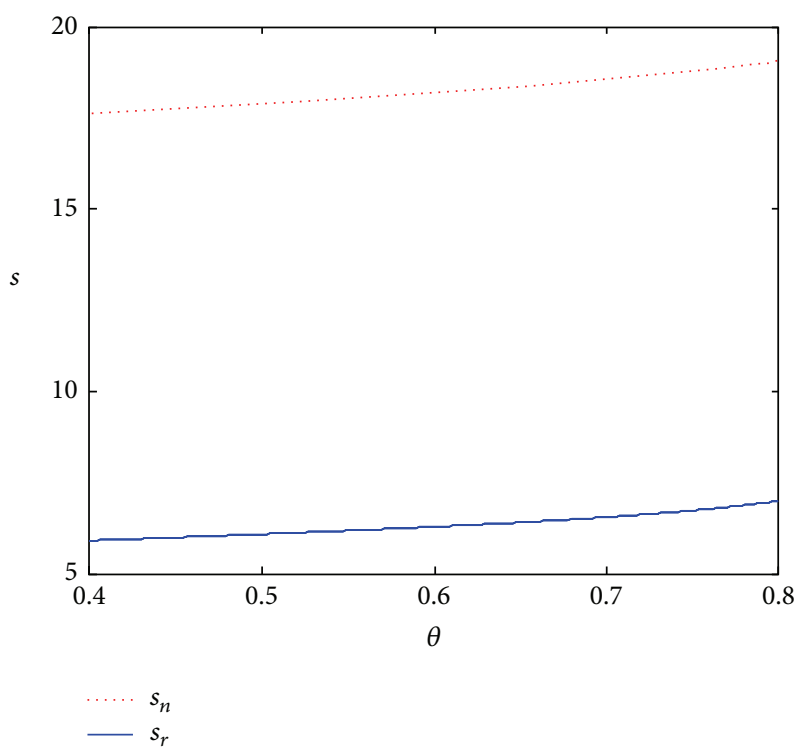

FIGURE 12: The influence of $\theta$ on $s_{n}, s_{r}$.

$$
\begin{aligned}
q_{n}^{N^{*}} & =\frac{3 \theta(1-\theta)^{2} \eta a}{\theta(1-\theta)[(9-\theta)(1-\theta) \eta-2]} \\
& +\frac{-\theta[(3-\theta)(1-\theta) \eta+1] c_{n}+[2 \theta(1-\theta) \eta+1] c_{r}}{\theta(1-\theta)[(9-\theta)(1-\theta) \eta-2]}, \\
q_{r}^{N^{*}} & =\frac{\theta(1-\theta)^{2} \eta a}{\theta(1-\theta)[(9-\theta)(1-\theta) \eta-2]} \\
& +\frac{\theta[4(1-\theta) \eta-1] c_{n}-[(3+\theta)(1-\theta) \eta-1] c_{r}}{\theta(1-\theta)[(9-\theta)(1-\theta) \eta-2]} \\
\Pi_{n} & =\left[(1-\theta) \eta-\frac{1}{2}\right] \eta s_{n}^{N^{* 2}}, \\
\Pi_{r} & =\left[\theta(1-\theta) \eta-\frac{1}{2}\right] \eta s_{r}^{N^{* 2}}, \\
\Pi_{s} & =\eta^{2}\left(s_{n}^{N^{* 2}}+2 \theta s_{n}^{N^{*}} s_{r}^{N^{*}}+\theta s_{r}^{N^{* 2}}\right) .
\end{aligned}
$$

\subsection{Effect of $\theta$ on Each Variable}

Proposition $19\left(\partial s_{n}^{N^{*}} / \partial \theta>0, \partial s_{r}^{N^{*}} / \partial \theta>0\right)$. It means, with increase of the customer acceptance of remanufactured product, both new and remanufactured products will increase service levels. The simulation is shown in Figure 12.

This proposition is similar to Propositions 9 and 14. The reasons and consequences do not repeat.

Proposition $20\left(\partial p_{n}^{N^{*}} / \partial \theta<0, \partial p_{r}^{N^{*}} / \partial \theta>0\right)$. It means, with the rise of $\theta$, new product price will reduce, and remanufactured product price will increase. The simulation is shown in Figure 13.

This proposition is similar to Propositions 10 and 15. The reasons and consequences do not repeat.

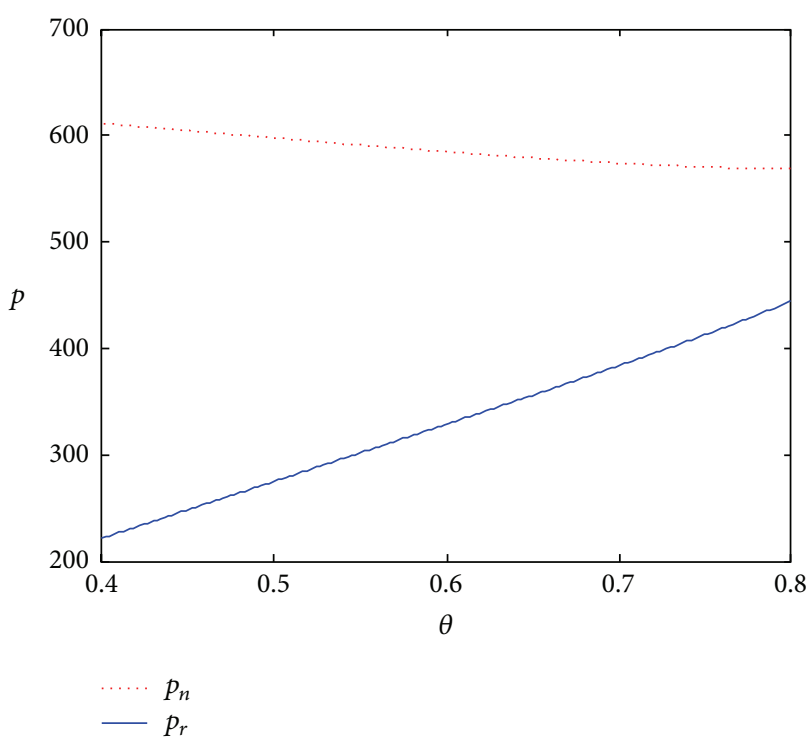

FIgURE 13: The influence of $\theta$ on $p_{n}, p_{r}$.

Proposition $21\left(\partial w_{n}^{N^{*}} / \partial \theta<0\right)$. It means, with the rise of $\theta$, the wholesale price of new product will reduce, while the change of remanufactured product wholesale price has an inflection point $w_{r}^{N^{* *}}$. When $\theta \in\left(0, w_{r}^{N^{* *}}\right), \partial w_{r}^{N^{*}} / \partial \theta>0$, and when $\theta \in\left(w_{r}^{N^{* *}}, 1\right), \partial w_{r}^{N^{*}} / \partial \theta<0$, where $w_{r}^{N^{* *}} \approx 9-6 \sqrt{2}$. It means remanufactured product wholesale price increases at the beginning and then decreases. The simulation is shown in Figure 14.

This proposition is similar to Propositions 11 and 16. The reasons and consequences do not repeat.

Proposition $22\left(\partial q_{n}^{N^{*}} / \partial \theta>0, \partial q_{r}^{N^{*}} / \partial \theta>0\right)$. It means, with the rise of $\theta$, new and remanufactured products' sales both improve. The simulation is shown in Figure 15.

This proposition is similar to Propositions 12 and 17. The reasons and consequences do not repeat.

Proposition $23\left(\partial \Pi_{n}^{N^{*}} / \partial \theta<0\right)$. It means, with the rise of $\theta$, the profit of new product will reduce. The change of remanufactured product profit has an inflection point $\Pi_{r}^{N^{* *}}$. When $\theta \epsilon$ $\left(0, \Pi_{r}^{N^{* *}}\right), \partial \Pi_{r}^{N^{*}} / \partial \theta>0$; when $\theta \in\left(\Pi_{r}^{N^{* *}}, 1\right), \partial \Pi_{r}^{N^{*}} / \partial \theta<0$, where $\Pi_{r}^{N^{* *}} \approx 9 / 17$. It means remanufactured product profit increases at the beginning and then decreases. $\partial \Pi_{s}^{N^{*}} / \partial \theta>0$. It means retailer profit increases continuously. The simulation is shown in Figure 16.

This proposition is similar to Propositions 13 and 18. The reasons and consequences do not repeat.

\section{Comparisons of Three Scenarios}

In this chapter, we will compare the service levels, prices, demands, and profits under three scenarios. 


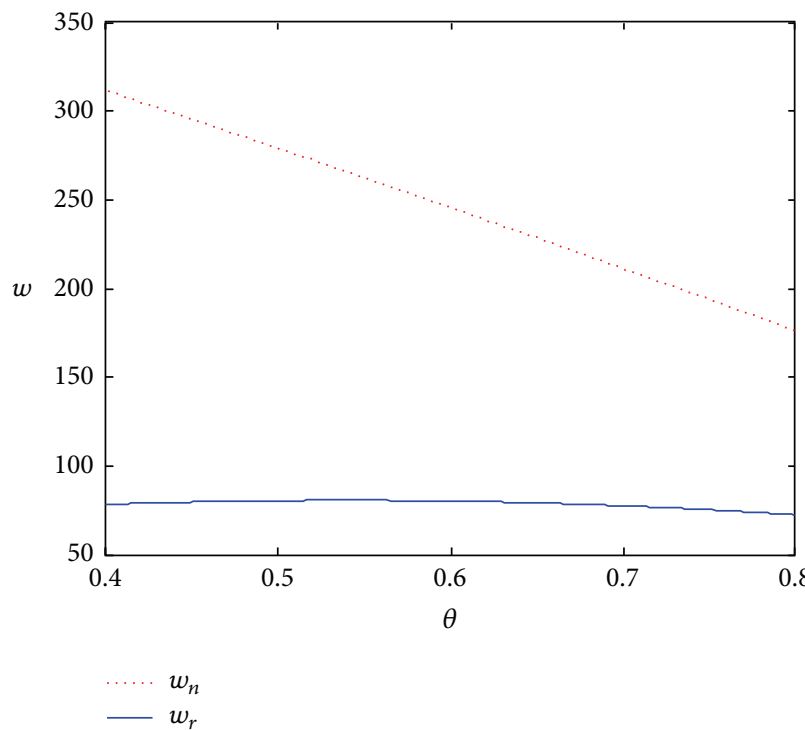

(a)

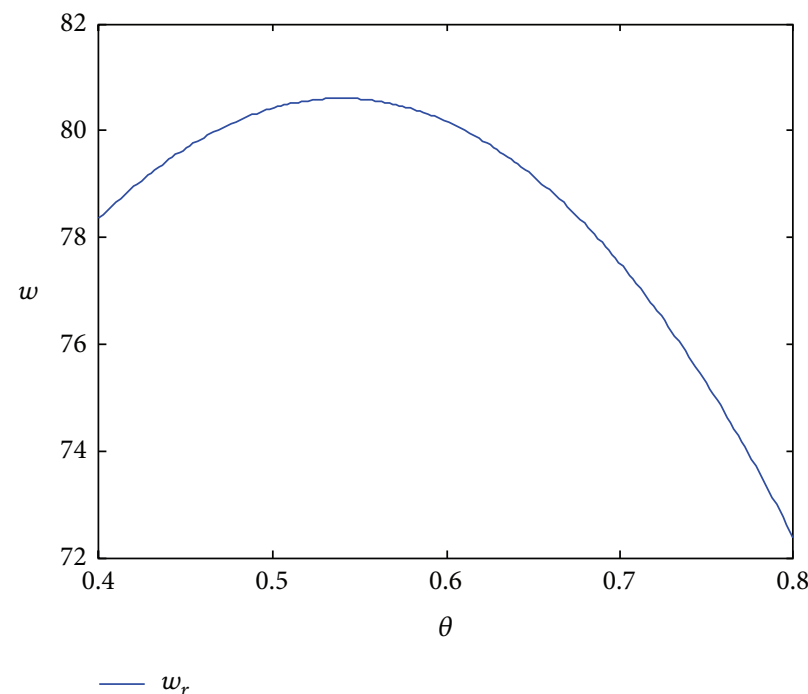

(b)

FIgURE 14: The influence of $\theta$ on $w_{n}, w_{r}$.

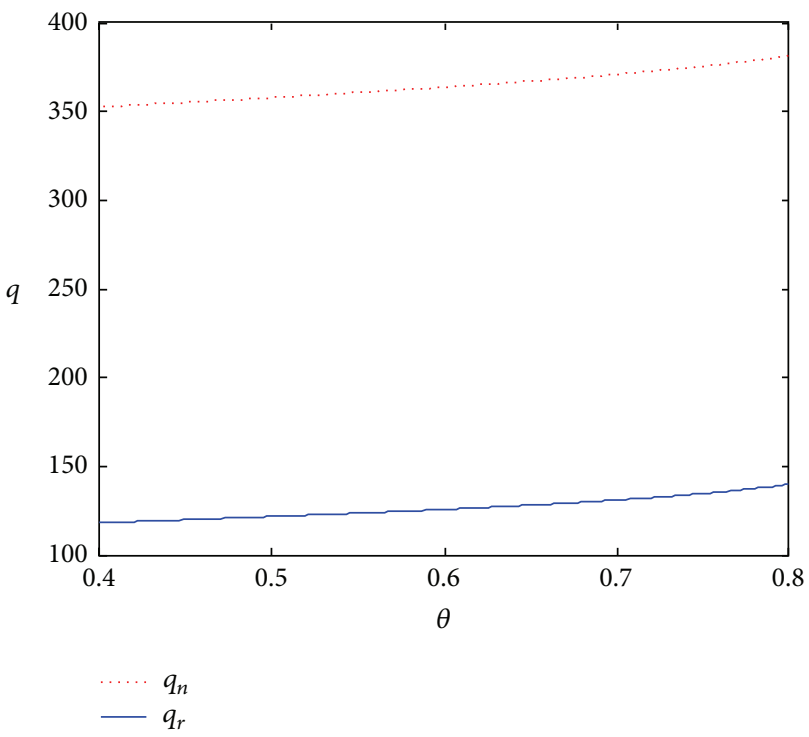

FIgURE 15: The influence of $\theta$ on $q_{n}, q_{r}$.

\subsection{Comparison of New Product}

Proposition $24\left(s_{n}^{M^{*}}=s_{n}^{S^{*}}<s_{n}^{N^{*}}, w_{n}^{S^{*}}<w_{n}^{N^{*}}<w_{n}^{M^{*}}\right.$, $\left.q_{n}^{M^{*}}=q_{n}^{S^{*}}<q_{n}^{N^{*}}, \Pi_{n}^{S^{*}}<\Pi_{n}^{N^{*}}<\Pi_{n}^{M^{*}}\right)$. For new product manufacturer, when it has leadership power, it will take higher wholesale price and get maximum profit. In Retailer Stackelberg, its wholesale price and profit are minimum.

Whether manufacturers or retailer dominates, new product will take lower service level and get lower sale. Whether in strong or weak position, it uses lower service level to reduce cost. In Nash Equilibrium, it uses higher service level to promote demand. At the same time, it has lower sales in strong or weak position and higher sale in equal status.

\subsection{Comparison of Remanufactured Product}

Proposition $25\left(s_{r}^{N^{*}}<s_{r}^{M^{*}}=s_{r}^{s^{*}}, w_{r}^{N^{*}}<w_{r}^{S^{*}}<w_{r}^{M^{*}}\right.$, $\left.q_{r}^{N^{*}}<q_{r}^{M^{*}}=q_{r}^{S^{*}}, \Pi_{r}^{N^{*}}<\Pi_{r}^{S^{*}}<\Pi_{r}^{M^{*}}\right)$. In Manufacturers Stackelberg, remanufactured product has the highest wholesale price and profit, which is corresponding to its leader status. But in weak position, its wholesale price and profit are higher than Nash Equilibrium; it seems contrary to common sense. This is because even though two manufacturers have equal positions, remanufactured product receives restriction and influence from new product inevitably. When manufacturers have weak powers, new product manufacturer has more restrictions and becomes conservative and gives less influence on remanufactured product. Remanufactured product can use higher service level and price to increase sales and gains more profit.

\subsection{Comparison of Retailer}

Proposition $26\left(p_{n}^{N^{*}}<p_{n}^{M^{*}}=p_{n}^{S^{*}}, p_{r}^{N^{*}}<p_{r}^{M^{*}}=p_{r}^{S^{*}}\right.$, $\Pi_{s}^{M^{*}}<\Pi_{s}^{N^{*}}<\Pi_{s}^{S^{*}}$ ). When participators have unequal powers, two kinds of products' retail prices are equal and higher. This is because when manufacturers are dominant, they will raise wholesale prices, which affects retail prices. When retailer is dominant, it will lower wholesale prices and still takes higher retail prices to gain more profit. On the contrary, retail prices and profits are lower in Nash Equilibrium.

But two kinds of unequal status are different in profit distributions. Although $p_{n}^{M^{*}}=p_{n}^{S^{*}}, p_{r}^{M^{*}}=p_{r}^{S^{*}}$; according to Propositions 24 and 25, $w_{n}^{S^{*}}<w_{n}^{M^{*}}, w_{r}^{S^{*}}<w_{r}^{M^{*}}$. In Manufacturer Stackelberg, manufacturers get more part $\left(w_{n}^{S^{*}}-c_{n}<\right.$ $\left.w_{n}^{M^{*}}-c_{n}, w_{r}^{S^{*}}-c_{r}<w_{r}^{M^{*}}-c_{r}\right)$; in Retailer Stackelberg, retailer gains more benefit $\left(p_{n}^{M^{*}}-w_{n}^{M^{*}}<p_{n}^{S^{*}}-w_{n}^{S^{*}}, p_{r}^{M^{*}}-w_{r}^{M^{*}}<\right.$ $\left.p_{r}^{S^{*}}-w_{r}^{S^{*}}\right)$ 


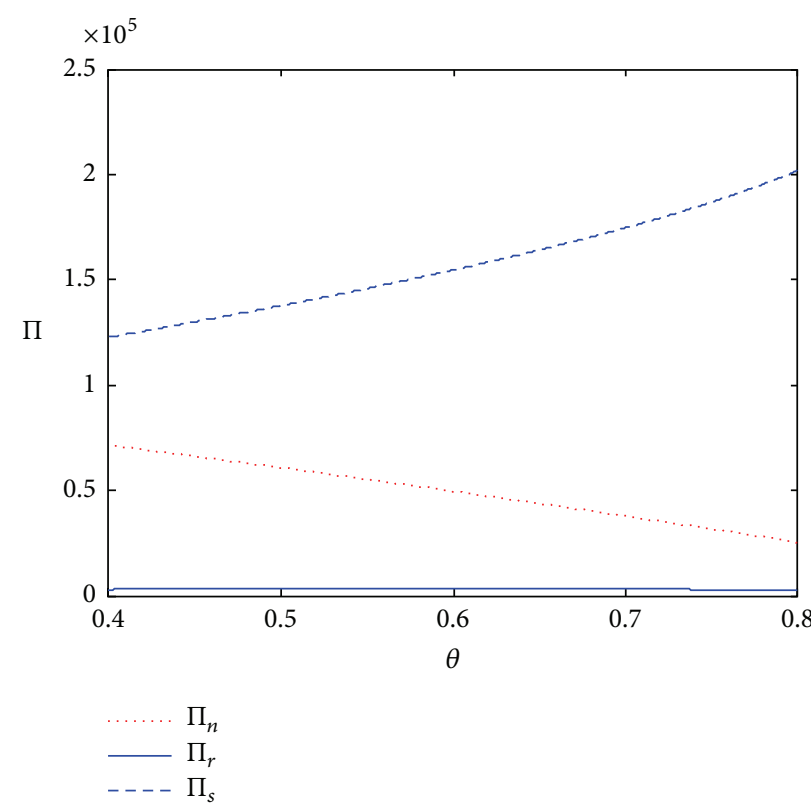

(a)

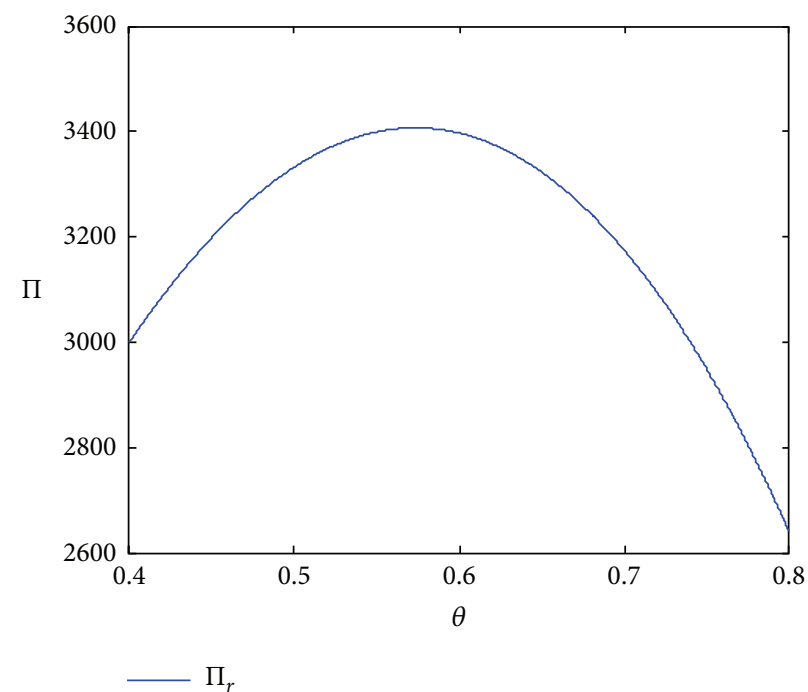

(b)

FIGURE 16: The influence of $\theta$ on $\Pi_{n}, \Pi_{r}$, and $\Pi_{s}$.

So retailer gets maximum profit in leadership position and gains minimum profit in disadvantaged position. The result is similar to new product.

\section{Conclusions and Future Research}

This paper discussed the optimal decision of prices, service levels, demands, and profits in three scenarios. With increase of customer acceptance of remanufactured product, new product raises service level and demand and reduces wholesale price and profit. Remanufactured product also increases service level and demand, while wholesale price and profit increase at the beginning and then decrease. New product retail price reduces, and remanufactured product retail price increases. As two kinds of products sales rise, retailer profit grows.

In Retailer Stackelberg, new product takes the lowest wholesale price and gets the lowest profit; remanufactured product takes medium wholesale price and medium profit; retailer obtains maximum retail price and gains the highest profit. In Manufacturers Stackelberg, new and remanufactured products can get the highest wholesale prices and obtain maximum profits; retailer gets higher retail price but gains minimum profit. In Nash Equilibrium, new product and retailer can get medium prices and profits because of equal powers; remanufactured product only gets the lowest price and profit.

Nonetheless, this paper has made several assumptions. Relaxing these assumptions may allow us to better comprehend the interactive dynamics in a closed-loop supply chain. So, the further research directions are as follows.

(1) This paper is based on a static single-cycle model. However, this model can be operated in the multicycle or even infinite periodic in normal conditions [14]. Atasu et al. [12] suggest that the recycling of waste product has two cases: (1) the number recovered is unlimited by the sale of new products; (2) the number recovered is limited by the new product sales in the previous phase. To simplify the analysis in this paper, we take the first case, assuming that there are enough waste materials for remanufacturing. Therefore, further research may consider a two-stage or multistage model, and the production of remanufacturing is restricted by the amount of new product sales, which can understand the production and marketing decisions deeply.

(2) To simplify the analysis, this study does not consider that new product manufacturer can impose restrictions on remanufactured product manufacturer, such as market access, brand licensing, and patent. The next research may consider adding these factors for further study.

(3) In this study, we assume that new and remanufactured product manufacturers have equal powers. However, remanufactured product is often affected by new product inevitably and has a relatively weak power in decision making. This paper is also aware of this factor in analysis. In future research, more reasonable assumption should be made in this area.

\section{Appendix}

In these proofs, based on Assumptions 7 and 8, we simplify the equals and then determine monotonicity.

Proof of Proposition 9. Consider

$$
\begin{aligned}
s_{n}^{s^{*}} & \approx \frac{1}{(4-\theta) \eta} a, \\
\frac{\partial s_{n}^{S^{*}}}{\partial \theta} & >0,
\end{aligned}
$$




$$
\begin{aligned}
s_{r}^{S^{*}} & \approx \frac{1}{2(4-\theta) \eta} a, \\
\frac{\partial s_{r}^{S^{*}}}{\partial \theta} & >0 .
\end{aligned}
$$

Proof of Proposition 10. Consider

$$
\begin{aligned}
p_{n}^{S^{*}} & \approx \frac{3(2-\theta)}{2(4-\theta)} a, \\
\frac{\partial p_{n}^{S^{*}}}{\partial \theta} & =\frac{-3}{(4-\theta)^{2}} a<0, \\
p_{r}^{S^{*}} & \approx \frac{\theta(5-2 \theta)}{2(4-\theta)} a, \\
\frac{\partial p_{r}^{S^{*}}}{\partial \theta} & =\frac{10-8 \theta+\theta^{2}}{(4-\theta)^{2}} a>0 .
\end{aligned}
$$

Proof of Proposition 11. Consider

$$
\begin{aligned}
w_{n}^{S^{*}} & \approx \frac{1-\theta}{4-\theta} a, \\
\frac{\partial w_{n}^{S^{*}}}{\partial \theta} & =\frac{-3}{(4-\theta)^{2}} a<0, \\
w_{r}^{S^{*}} & \approx \frac{\theta(1-\theta)}{2(4-\theta)} a, \\
\frac{\partial w_{r}^{S^{*}}}{\partial \theta} & =\frac{\theta^{2}-8 \theta+4}{(4-\theta)^{2}} a .
\end{aligned}
$$

When $0<\theta<4-2 \sqrt{3}, \partial w_{r}^{S^{*}} / \partial \theta>0$, and when $4-2 \sqrt{3}<$ $\theta<1, \partial w_{r}^{S^{*}} / \partial \theta<0$.

Proof of Proposition 12. Consider

$$
\begin{aligned}
q_{n}^{S^{*}} & \approx \frac{1}{4-\theta} a, \\
\frac{\partial q_{n}^{S^{*}}}{\partial \theta} & >0, \\
q_{r}^{S^{*}} & \approx \frac{1}{2(4-\theta)} a, \\
\frac{\partial q_{r}^{S^{*}}}{\partial \theta} & >0 .
\end{aligned}
$$

Proof of Proposition 13. Consider

$$
\begin{aligned}
\Pi_{n}^{S^{*}} & \approx \frac{1-\theta}{(4-\theta)^{2}} a^{2}, \\
\frac{\partial \Pi_{n}^{S^{*}}}{\partial \theta} & =-\frac{2+\theta}{(4-\theta)^{2}} a^{2}<0,
\end{aligned}
$$

$$
\begin{aligned}
\Pi_{r}^{S^{*}} & \approx \frac{\theta(1-\theta)}{4(4-\theta)^{2}} a^{2}, \\
\frac{\partial \Pi_{r}^{S^{*}}}{\partial \theta} & =\frac{4-7 \theta}{4(4-\theta)^{2}} a^{2} .
\end{aligned}
$$

When $0<\theta<4 / 7, \partial \Pi_{r}^{S^{*}} / \partial \theta>0$, and when $4 / 7<\theta<1$, $\partial \Pi_{r}^{S^{*}} / \partial \theta<0$,

$$
\begin{aligned}
\Pi_{s}^{S^{*}} & \approx \frac{2+\theta}{4(4-\theta)} a^{2}, \\
\frac{\partial \Pi_{s}^{S^{*}}}{\partial \theta} & >0 .
\end{aligned}
$$

Proof of Proposition 14. Consider

$$
\begin{aligned}
s_{n}^{M^{*}} & \approx \frac{a}{(4-\theta) \eta}, \\
\frac{\partial s_{n}^{M^{*}}}{\partial \theta} & >0, \\
s_{r}^{M^{*}} & \approx \frac{a}{2(4-\theta) \eta}, \\
\frac{\partial s_{r}^{M^{*}}}{\partial \theta} & >0 .
\end{aligned}
$$

Proof of Proposition 15. Consider

$$
\begin{aligned}
p_{n}^{M^{*}} & \approx \frac{3 a}{2}-\frac{3}{4-\theta} a, \\
\frac{\partial p_{n}^{M^{*}}}{\partial \theta} & <0, \\
p_{r}^{M^{*}} & \approx \frac{\theta(5-2 \theta)}{2(4-\theta)} a, \\
\frac{\partial p_{r}^{M^{*}}}{\partial \theta} & =\frac{\theta^{2}-8 \theta+10}{(4-\theta)^{2}} a .
\end{aligned}
$$

Because $0<\theta<1, \partial p_{r}^{M^{*}} / \partial \theta>0$.

Proof of Proposition 16. Consider

$$
\begin{aligned}
w_{n}^{M^{*}} & \approx \frac{1-\theta}{4-\theta} 2 a=\left(1-\frac{3}{4-\theta}\right) 2 a, \\
\frac{\partial w_{n}^{M^{*}}}{\partial \theta} & <0, \\
w_{r}^{M^{*}} & \approx \frac{\theta(1-\theta)}{4-\theta} a, \\
\frac{\partial w_{r}^{M^{*}}}{\partial \theta} & =\frac{\theta^{2}-8 \theta+4}{(4-\theta)^{2}} a .
\end{aligned}
$$

When $0<\theta<4-2 \sqrt{3}, \partial w_{r}^{M^{*}} / \partial \theta>0$, and when $4-2 \sqrt{3}<$ $\theta<1, \partial w_{r}^{M^{*}} / \partial \theta<0$. 
Proof of Proposition 17. Consider

$$
\begin{aligned}
q_{n}^{M^{*}} & \approx \frac{a}{4-\theta}, \\
\frac{\partial q_{n}^{M^{*}}}{\partial \theta} & >0, \\
q_{r}^{M^{*}} & \approx \frac{a}{2(4-\theta)}, \\
\frac{\partial q_{r}^{M^{*}}}{\partial \theta} & >0 .
\end{aligned}
$$

Proof of Proposition 18. Consider

$$
\begin{aligned}
\Pi_{n}^{M^{*}} & \approx \frac{1-\theta}{(4-\theta)^{2}} 2 a^{2}, \\
\frac{\partial \Pi_{n}^{M^{*}}}{\partial \theta} & =-\frac{2(\theta+2)}{(4-\theta)^{3}} a^{2}<0, \\
\Pi_{r}^{M^{*}} & \approx \frac{\theta(1-\theta)}{2(4-\theta)^{2}} a^{2}, \\
\frac{\partial \Pi_{r}^{M^{*}}}{\partial \theta} & =\frac{a^{2}}{2} \frac{4-7 \theta}{(4-\theta)^{3}} .
\end{aligned}
$$

When $0<\theta<4 / 7, \partial \Pi_{r}^{M^{*}} / \partial \theta>0$, and when $4 / 7<\theta<1$, $\partial \Pi_{r}^{M^{*}} / \partial \theta<0$,

$$
\begin{gathered}
\Pi_{s}^{M^{*}} \approx \frac{4+5 \theta}{4(4-\theta)^{2}} a^{2}, \\
\frac{\partial \Pi_{s}^{M^{*}}}{\partial \theta}=\frac{a^{2}}{4} \frac{28+5 \theta}{(4-\theta)^{3}}>0 .
\end{gathered}
$$

Proof of Proposition 19. Consider

$$
\begin{aligned}
s_{n}^{N^{*}} & \approx \frac{3 a}{(9-\theta) \eta}, \\
\frac{\partial s_{n}^{N^{*}}}{\partial \theta} & >0 \\
s_{r}^{N^{*}} & \approx \frac{a}{(9-\theta) \eta}, \\
\frac{\partial s_{r}^{N^{*}}}{\partial \theta} & >0 .
\end{aligned}
$$

Proof of Proposition 20. Consider

$$
\begin{aligned}
p_{n}^{N^{*}} & \approx \frac{6-2 \theta}{9-\theta} a, \\
\frac{\partial p_{n}^{N^{*}}}{\partial \theta} & =\frac{-12}{(9-\theta)^{2}} a<0, \\
p_{r}^{N^{*}} & \approx \frac{\theta(5-\theta)}{9-\theta} a, \\
\frac{\partial p_{r}^{N^{*}}}{\partial \theta} & =\frac{\theta^{2}-18 \theta+45}{(9-\theta)^{2}} a>0 .
\end{aligned}
$$

Proof of Proposition 21. Consider

$$
\begin{aligned}
w_{n}^{N^{*}} & \approx \frac{3(1-\theta) a}{9-\theta}, \\
\frac{\partial w_{n}^{N^{*}}}{\partial \theta} & =\frac{-24}{(9-\theta)^{2}} a<0, \\
w_{r}^{N^{*}} & \approx \frac{\theta(1-\theta) a}{9-\theta}, \\
\frac{\partial w_{r}^{N^{*}}}{\partial \theta} & =\frac{9-18 \theta+\theta^{2}}{(9-\theta)^{2}} a .
\end{aligned}
$$

When $0<\theta<9-6 \sqrt{2}, \partial w_{r}^{N^{*}} / \partial \theta>0$, and when $9-6 \sqrt{2}<$ $\theta<1, \partial w_{r}^{N^{*}} / \partial \theta<0$.

Proof of Proposition 22. Consider

$$
\begin{gathered}
q_{n}^{N^{*}} \approx \frac{3 a}{9-\theta}, \\
\frac{\partial q_{n}^{N^{*}}}{\partial \theta}>0, \\
q_{r}^{N^{*}} \approx \frac{a}{9-\theta}, \\
\frac{\partial q_{r}^{N^{*}}}{\partial \theta}>0 .
\end{gathered}
$$

Proof of Proposition 23. Consider

$$
\begin{gathered}
\Pi_{n}^{N^{*}} \approx \frac{9(1-\theta) a^{2}}{(9-\theta)^{2}}, \\
\frac{\partial \Pi_{n}^{N^{*}}}{\partial \theta}=-\frac{9(\theta+7)}{(9-\theta)^{3}} a^{2}<0,
\end{gathered}
$$




$$
\begin{aligned}
\Pi_{r}^{N^{*}} & \approx \frac{\theta(1-\theta) a^{2}}{(9-\theta)^{2}}, \\
\frac{\partial \Pi_{r}^{N^{*}}}{\partial \theta} & =\frac{9-17 \theta}{(9-\theta)^{3}} a^{2} .
\end{aligned}
$$

When $0<\theta<9 / 17, \partial \Pi_{r}^{N^{*}} / \partial \theta>0$, and when $9 / 17<\theta<$ $1, \partial \Pi_{r}^{N^{*}} / \partial \theta<0$,

$$
\begin{gathered}
\Pi_{s}^{N^{*}} \approx \frac{(9+7 \theta) a^{2}}{(9-\theta)^{2}}, \\
\frac{\partial \Pi_{r}^{N^{*}}}{\partial \theta}=\frac{81+7 \theta}{(9-\theta)^{3}} a^{2}>0 .
\end{gathered}
$$

\section{Conflict of Interests}

The authors declare that there is no conflict of interests regarding the publication of this paper.

\section{Acknowledgment}

This research is partially supported by National Nature Science Foundation of China (nos. 71172016 and 71332003).

\section{References}

[1] W. Hauser and R. Lund, Remanufacturing: Operating Practices and Strategies, Boston University, Boston, Mass, USA, 2008.

[2] G. Iyer, "Coordinating channels under price and nonprice competition," Marketing Science, vol. 17, no. 4, pp. 338-355, 1998.

[3] A. A. Tsay and N. Agrawal, "Channel dynamics under price and service competition," Manufacturing \& Service Operations Management, vol. 2, no. 4, pp. 372-391, 2000.

[4] J. S. Raju and Z. J. Zhang, "Channel coordination in the presence of a dominant retailer," Marketing Science, vol. 24, no. 2, pp. 254262, 2005.

[5] C. Koulamas, "A newsvendor problem with revenue sharing and channel coordination," Decision Sciences, vol. 37, no. 1, pp. 91100, 2006.

[6] S. Ba, J. Stallaert, and Z. Zhang, "Oligopolistic price competition and adverse price effect in online retailing markets," Decision Support Systems, vol. 45, no. 4, pp. 858-869, 2008.

[7] F. Bernstein and A. Federgruen, "Coordination mechanisms for supply chains under price and service competition," Manufacturing and Service Operations Management, vol. 9, no. 3, pp. 242-262, 2007.

[8] B. de Borger and K. van Dender, "Prices, capacities and service levels in a congestible Bertrand duopoly," Journal of Urban Economics, vol. 60, no. 2, pp. 264-283, 2006.
[9] J. C. Darian, A. R. Wiman, and L. A. Tucci, "Retail patronage intentions: the relative importance of perceived prices and salesperson service attributes," Journal of Retailing and Consumer Services, vol. 12, no. 1, pp. 15-23, 2005.

[10] B. Dan, G. Xu, and C. Liu, "Pricing policies in a dual-channel supply chain with retail services," International Journal of Production Economics, vol. 139, no. 1, pp. 312-320, 2012.

[11] H. Kurata and S.-H. Nam, "After-sales service competition in a supply chain: optimization of customer satisfaction level or profit or both?" International Journal of Production Economics, vol. 127, no. 1, pp. 136-146, 2010.

[12] A. Atasu, M. Sarvary, and L. N. V. Wassenhove, "Remanufacturing as a marketing strategy," Management Science, vol. 54, no. 10, pp. 1731-1746, 2008.

[13] L. G. Debo, L. B. Toktay, and L. N. van Wassenhove, "Market segmentation and product technology selection for remanufacturable products," Management Science, vol. 51, no. 8, pp. $1193-$ 1205, 2005.

[14] G. Ferrer and J. M. Swaminathan, "Managing new and remanufactured products," Management Science, vol. 52, no. 1, pp. 15$26,2006$.

[15] V. D. R. Guide Jr. and L. N. van Wassenhove, "The evolution of closed-loop supply chain research," Operations Research, vol. 57, no. 1, pp. 10-18, 2009.

[16] C.-F. Hsueh, "An inventory control model with consideration of remanufacturing and product life cycle," International Journal of Production Economics, vol. 133, no. 2, pp. 645-652, 2011.

[17] S. Mitra and S. Webster, "Competition in remanufacturing and the effects of government subsidies," International Journal of Production Economics, vol. 111, no. 2, pp. 287-298, 2008.

[18] S. Pokharel and Y. Liang, "A model to evaluate acquisition price and quantity of used products for remanufacturing," International Journal of Production Economics, vol. 138, no. 1, pp. 170-176, 2012.

[19] A. Robotis, S. Bhattacharya, and L. N. van Wassenhove, "The effect of remanufacturing on procurement decisions for resellers in secondary markets," European Journal of Operational Research, vol. 163, no. 3, pp. 688-705, 2005.

[20] R. C. Savaskan, S. Bhattacharya, and L. N. Van Wassenhove, "Closed-loop supply chain models with product remanufacturing," Management Science, vol. 50, no. 2, pp. 239-252, 2004.

[21] R. C. Savaskan and L. N. van Wassenhove, "Reverse channel design: the case of competing retailers," Management Science, vol. 52, no. 1, pp. 1-14, 2006.

[22] S. Vadde, A. Zeid, and S. V. Kamarthi, "Pricing decisions in a multi-criteria setting for product recovery facilities," Omega, vol. 39, no. 2, pp. 186-193, 2011.

[23] P. Majumder and H. Groenevelt, "Competition in remanufacturing," Production and Operations Management, vol. 10, no. 2, pp. 125-141, 2001.

[24] M. E. Ferguson and L. B. Toktay, "The effect of competition on recovery strategies," Production and Operations Management, vol. 15, no. 3, pp. 351-368, 2006.

[25] C. Gray and M. Charter, Remanufacturing and Product Design: Designing for the 7th Generation, The Centre for Sustainable Design University College for the Creative Arts, Farnham, UK, 2007. 
[26] S. Gupta and R. Loulou, "Process innovation, production differentiation, and channel structure: strategic incentives in a duopoly," Marketing Science, vol. 17, no. 4, pp. 301-316, 1998.

[27] G. Ferrer and M. E. Ketzenberg, "Value of information in remanufacturing complex products," IIE Transactions, vol. 36, no. 3, pp. 265-277, 2004.

[28] Y. Xia and S. M. Gilbert, "Strategic interactions between channel structure and demand enhancing services," European Journal of Operational Research, vol. 181, no. 1, pp. 252-265, 2007. 


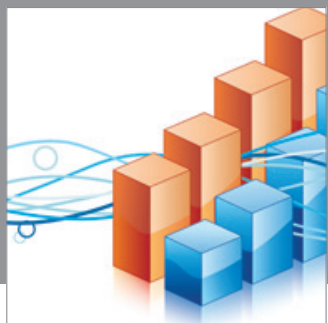

Advances in

Operations Research

mansans

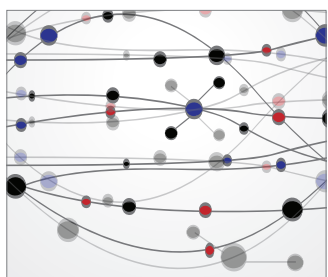

The Scientific World Journal
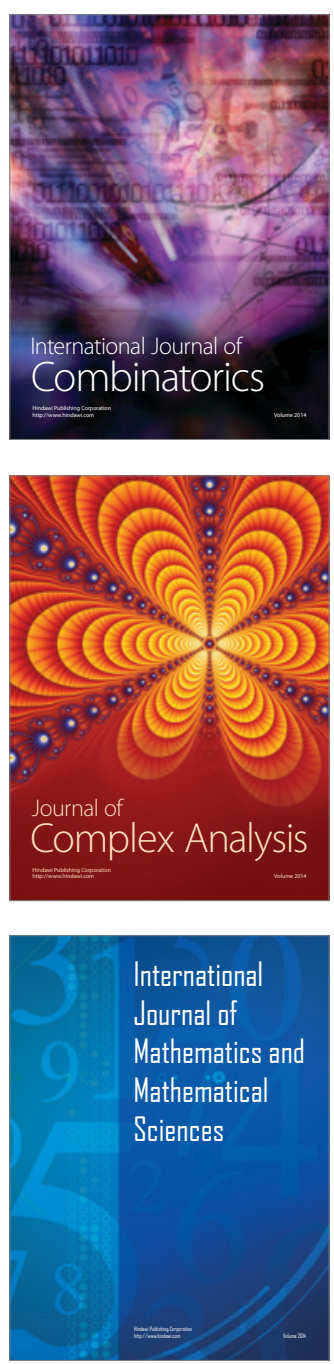
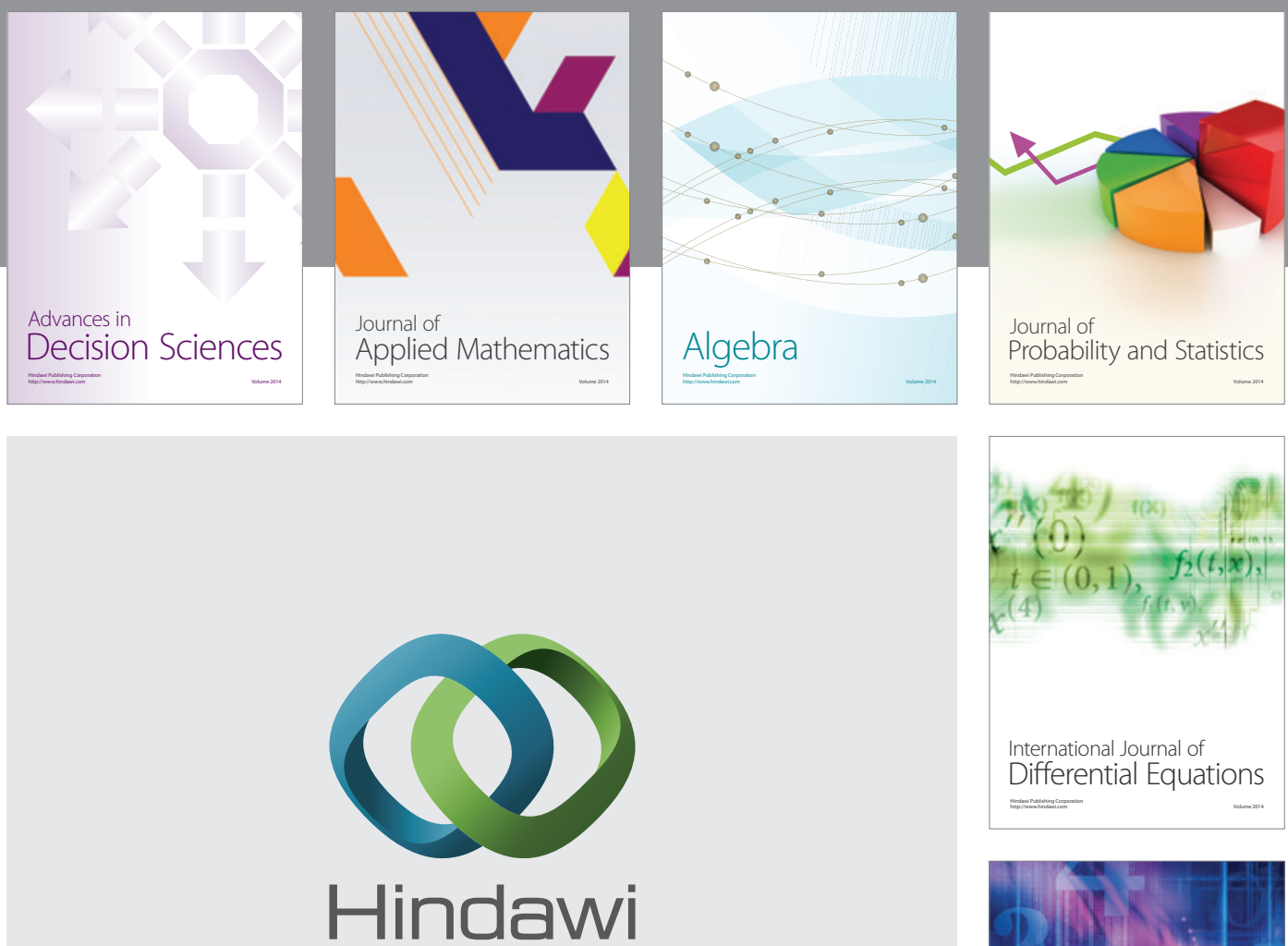

Submit your manuscripts at http://www.hindawi.com
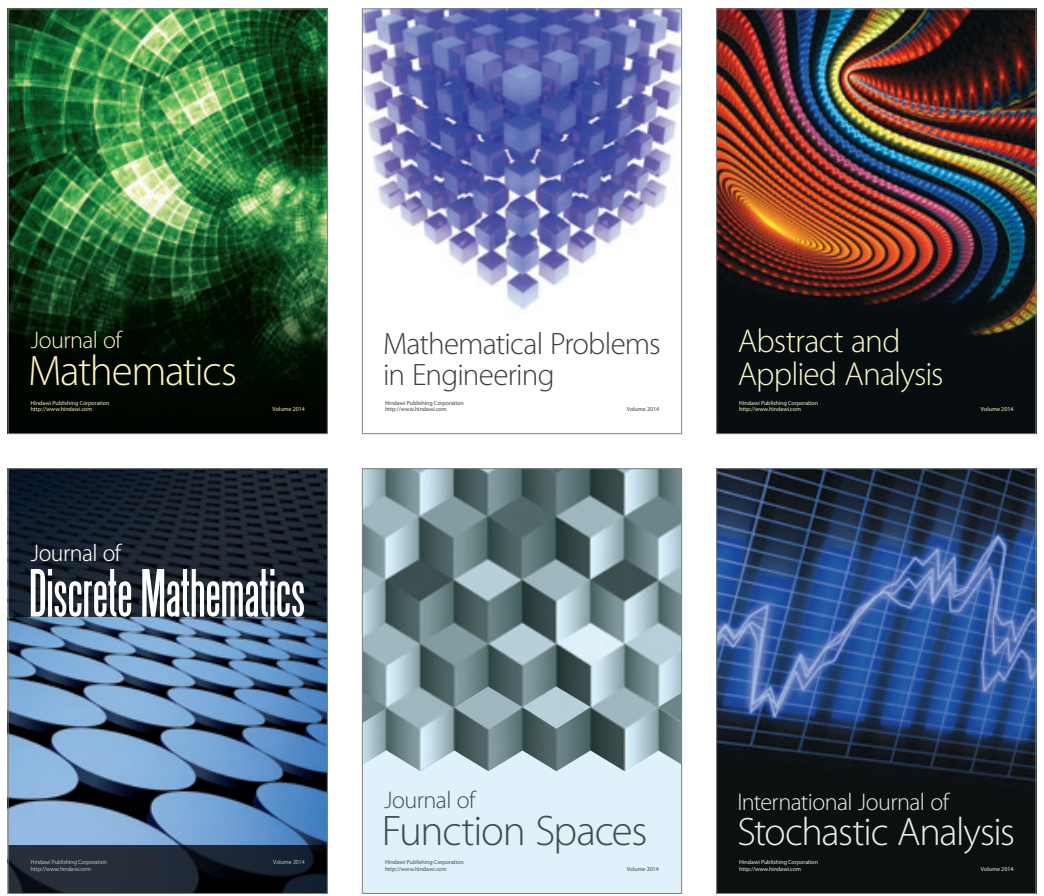

Journal of

Function Spaces

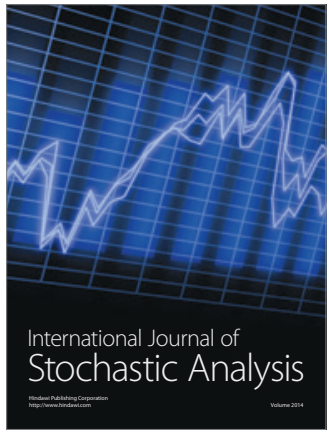

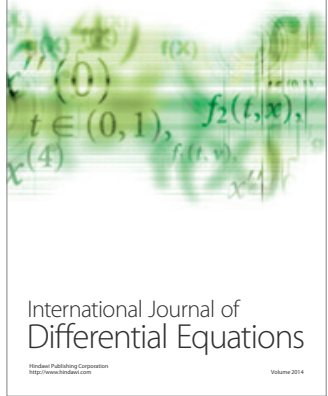
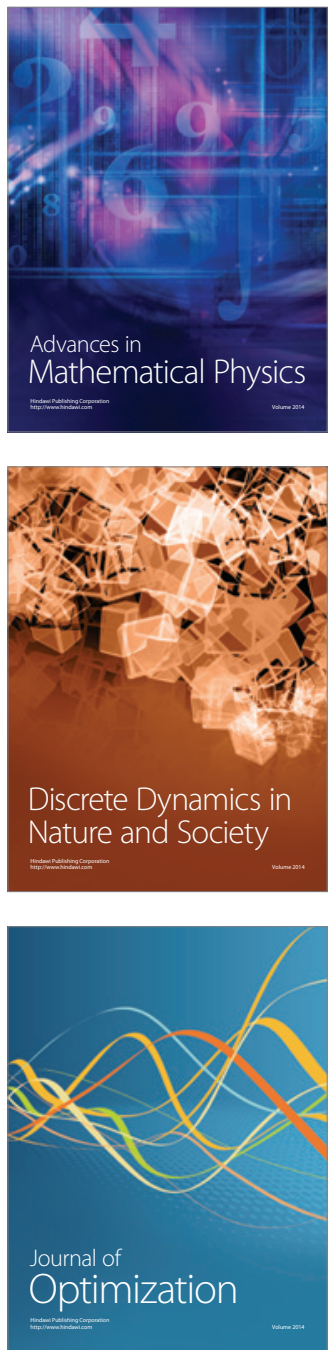